

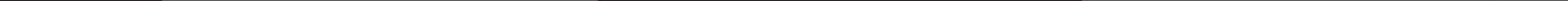




\section{Medición y análisis de las condiciones de trabajo decente en las zonas geográ- ficas de Colombia: cabeceras y centros poblados y rural disperso 2013-2015 ${ }^{1}$}

Por Carmen Lucía Tangarife López ${ }^{2}$

\section{Introducción}

$\mathrm{L}$

a Organización Internacional del Trabajo (OIT) ha identificado que las actividades económicas se desarrollan bajo formas que han puesto en riesgo a los trabajadores y su calidad de vida. Ante dicha situación, el organismo internacional ha hecho un llamado y ha invitado a los países a pensar seriamente en esto, y por ello, ha propuesto una batería de indicadores agrupados en diez dimensiones para medir el trabajo decente, los cuales fueron tenidos en cuenta en este artículo.

El interés por realizar la medición de trabajo decente en las zonas geográficas (urbana-rural) es evidenciar las enormes brechas existentes entre las condiciones de los trabajadores urbanos y rurales, y reforzar la necesidad de una Reforma Rural Integral que siente las bases para la transformación estructural del campo y cree condiciones de bienestar para su población, a través del trabajo decente, tal como lo plantea el

Artículo recibido en agoto de 2106.

Artículo aprobado en octubre de 2016.

2 Economista y Magíster en Economía de la Universidad de Antioquia. Profesional en el Área de Investigación de la Escuela Nacional Sindical. 
punto uno del Acuerdo Final entre el Gobierno Nacional y las FARC-EP, específicamente el numeral 1.3.3.5 que establece la necesidad de formular un plan progresivo de protección social y de garantías de derechos de los trabajadores y trabajadoras rurales (República de Colombia, 2016).

Es importante destacar que una de las dificultades principales para medir el trabajo decente en la zona rural tiene que ver con la disponibilidad y debilidad de la información a este nivel de desagregación, ya que las encuestas disponibles no tienen la capacidad de recoger las particularidades de los trabajadores rurales, su estacionalidad y temporalidad, y la multiplicidad de actividades en la que ocupan su tiempo. Adicionalmente, el ingreso rural se mide de la misma manera que el ingreso de las zonas urbanas (Departamento Nacional de Planeación, 2015). Por tal motivo, para contar con información más precisa es necesario realizar una encuesta exclusiva a los hogares rurales, puesto que esta tiene grandes ventajas, por un lado, permite medir el empleo rural en un periodo corto y también a través de una metodología más ajustada a las características del trabajo y del proceso de trabajo rural en un tiempo largo (año calendario) y, por el otro, facilita realizar comparaciones con los datos de las encuestas del área urbana y disponer de nuevos parámetros sobre las especificidades del empleo rural (Martínez, 1992).

Si bien la información es limitada, en este caso para la medición de los indicadores de trabajo decente se utilizó la Gran Encuesta Integrada de Hogares (GEIH) del Departamento Administrativo Nacional de Estadística (DANE) y en algunos indicadores se recurrió a información recolectada por instituciones como la Federación de Aseguradores Colombianos (Fasecolda), el Ministerio del Trabajo y la Escuela Nacional Sindical (ENS). El período de análisis fue 2013-2015, bajo la agregación de datos anuales ${ }^{3}$.

Vale la pena aclarar que como la mayoría de la ocupación en la zona resto se concentró en el sector de la agricultura, ganadería, caza, silvicultura y pesca, algunos indicadores, para las que no existe información diferenciada para la zona 
En este sentido, este artículo se desarrolla en tres apartados; en primer lugar, se explica el origen del concepto de trabajo decente; en segundo lugar, se presenta un breve contexto social de las zonas geográficas, ya que los indicadores no pueden ser leídos ni interpretados por fuera del mismo; en tercer lugar, se exponen una a una las diez dimensiones y se miden sus respectivos indicadores. Finalmente, se encuentran algunas consideraciones y recomendaciones que aportan a la toma de decisiones, así como también se espera que permitan contrastar, profundizar o remover ideas preconcebidas.

\section{1. ¿Qué es el concepto Trabajo Decente?}

En 1999 la Organización Internacional del Trabajo (OIT) propuso a sus miembros y a todos los países del mundo una concepción sobre el trabajo: la del Trabajo Decente (TD). El TD surge debido a las trasformaciones del trabajo en los procesos de globalización, en donde se presentó una flexibilización de las relaciones laborales con una paralela precarización laboral que respondía, a su vez, a las nuevas formas de organización productiva y las dinámicas de integración comercial que se estaban generando. Juan Somavía, director del organismo en ese entonces, instó a promoverlo a raíz del reconocimiento de grandes problemas de desprotección laboral y por una acentuada preocupación por el aumento de condiciones laborales degradantes en el contexto global junto con una profundización de la globalización.

En general, el concepto de TD hace referencia a la focalización de las acciones de la OIT en cuatro objetivos/pilares estratégicos que tienen como eje transversal la igualdad de género:

resto, serán analizados bajo el comportamiento que tuvo este sector, de manera que se pueda observar la tendencia y contar con un panorama aproximado de las condiciones de trabajo decente de la zona resto. 
1. Crear trabajo: se requiere de una economía que genere oportunidades de inversión, iniciativa empresarial, desarrollo de calificaciones, puestos de trabajo y modos de vida sostenibles.

2. Garantizar los derechos de los trabajadores: para lograr el reconocimiento y el respeto de los derechos de los trabajadores. De todos los trabajadores, y en particular de los trabajadores desfavorecidos o pobres que necesitan representación, participación y leyes adecuadas que se cumplan y estén a favor, y no en contra, de sus intereses.

3. Extender la protección social: para promover tanto la inclusión social como la productividad al garantizar que mujeres y hombres disfruten de condiciones de trabajo seguras, que les proporcionen tiempo libre y descanso adecuados, que tengan en cuenta los valores familiares y sociales, que contemplen una retribución adecuada en caso de pérdida o reducción de los ingresos, y que permitan el acceso a una asistencia sanitaria apropiada.

4. Promover el diálogo social: la participación de organizaciones de trabajadores y de empleadores, sólidas e independientes, es fundamental para elevar la productividad, evitar los conflictos en el trabajo, así como para crear sociedades cohesionadas.

En general, el trabajo decente sintetiza las aspiraciones de las personas durante su vida laboral. Significa la oportunidad de acceder a un empleo productivo que genere un ingreso justo, la seguridad en el lugar de trabajo y la protección social para las familias, mejores perspectivas de desarrollo personal e integración social, libertad para que los individuos expresen sus opiniones, se organicen y participen en las decisiones que afectan sus vidas, y la igualdad de oportunidades y trato para todos, mujeres y hombres (Organización Internacional del Trabajo, 2016). 
Para la medición de TD se establecieron diez elementos fundamentales, dimensiones que corresponden a los cuatro pilares estratégicos mencionados anteriormente, además de un elemento adicional relacionado con el contexto económico y social para el trabajo decente. En la siguiente tabla se aprecian cada una de las dimensiones.

\section{Tabla 1. Dimensiones analíticas del Trabajo Decente (TD)}

\begin{tabular}{lc}
\hline Dimensiones analíticas de Trabajo Decente & Pilar Estratégico \\
\hline 1. Oportunidades de empleo & $(1+2)$ \\
\hline 2. Ingresos adecuados y trabajo productivo & $(1+3)$ \\
\hline 3. Tiempo de trabajo decente & $(1+3)$ \\
\hline 4. Conciliación del trabajo, la vida familiar y la vida personal & $(1+3)$ \\
\hline 5. Trabajo que debería ser abolido & $(1+3)$ \\
\hline 6. Estabilidad y seguridad del trabajo & $(1,2+3)$ \\
\hline 7. Igualdad de oportunidades y trato en el empleo & $(1,2+3)$ \\
\hline 8. Entorno de trabajo seguro & $(1+3)$ \\
\hline 9. Seguridad social & $(1+3)$ \\
\hline $\begin{array}{l}\text { 10. Diálogo social y representación de } \\
\text { empleadores y trabajadores }\end{array}$ & $(1+4)$ \\
\hline
\end{tabular}

11. Contexto económico y social para el trabajo decente

\section{Contexto social de los centros poblados y rural disperso}

2.1 Perfil de la población que habita en la zona resto

Para el 2015, Colombia registró una población superior a los 46,8 millones de habitantes, $77 \%$ de ellos vivían en la cabecera del país y el $23 \%$ restante en la zona rural (denominada centros poblados y rural disperso o resto en las estadísticas del DANE). Del total de la población de la zona resto, un 52,9\% eran hombres y un 47,1\% eran mujeres. 
Según la Encuesta de Calidad de Vida, a 2015, tanto en la cabecera como en la zona resto, había más hogares que viviendas: el número de hogares registrados supera en un 2,8\% y 1,4\% respectivamente al número de viviendas disponibles, lo que quiere decir que hay viviendas en donde habita más de un hogar. Mientras que en la cabecera, el tamaño promedio del hogar fue de 3,3 personas en la zona resto fue de 3,6 . En esta última zona el $28 \%$ de los hogares se constituían por cinco o más personas; $20,5 \%$ por cuatro personas; $19,8 \%$ por tres personas; $17,6 \%$ por dos personas y $14,1 \%$ por una persona.

Tabla 2. Indicadores de población por zona 2015

\begin{tabular}{|llll|}
\hline Zona & Viviendas & Hogares & $\begin{array}{l}\text { Personas por hogar } \\
\text { promedio }\end{array}$ \\
\hline Cabecera & 10.826 .000 & 11.126 .000 & 3,3 \\
\hline $\begin{array}{l}\text { Centros poblados y } \\
\text { rural disperso }\end{array}$ & 2.933 .000 & 2.974 .000 & 3,6 \\
\hline
\end{tabular}

Fuente: Encuesta Nacional de Calidad de Vida. DANE

Con respecto al acceso a los servicios públicos en la zona resto, se encontró que el servicio de energía eléctrica llegaba al 95,6\% de los hogares; el servicio de acueducto tuvo una cobertura de 61,2\%; el servicio de alcantarillado estaba disponible para el 16,8\% de los hogares; los hogares con acceso al servicio de gas natural fueron $11,7 \%$; el servicio de recolección de basuras alcanzó una cobertura de 26,1 \% y la cobertura de telefonía fue de solo el 2,5\% . La baja cobertura evidenciada en los servicios públicos es bastante crítica, no solo por las grandes brechas urbano-rurales, sino por su valor intrínseco como derechos fundamentales (Departamento Nacional de Planeación, 2014). 


\section{Gráfico 1. Acceso a servicios públicos por zona 2015}

\section{Porcentaje de cobertura}

Cabecera

Resto

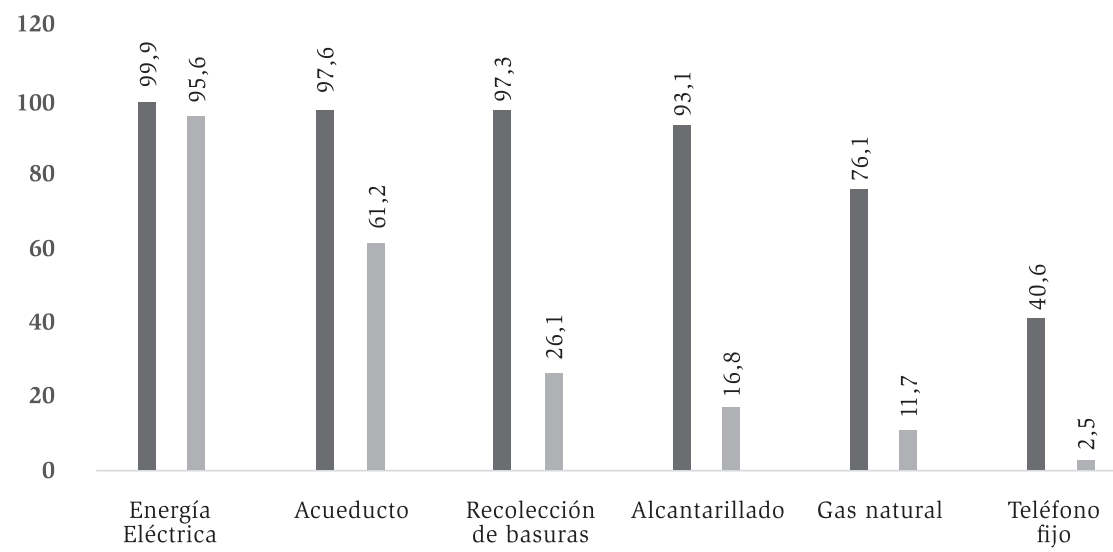

Fuente: Encuesta Nacional de Calidad de Vida. DANE

\subsection{Contexto social}

Existen diferencias importantes en términos de igualdad de oportunidades entre la población urbana y la población rural. La incidencia de la pobreza rural es mayor que la urbana tanto en ingresos como en pobreza multidimensional, los pobladores de las zonas rurales tienen menores oportunidades de desarrollarse plenamente y como consecuencia existen muy pocas posibilidades de que generación tras generación mejoren su condición socioeconómica (Departamento Nacional de Planeación, 2014). Para el 2015, la tasa de pobreza monetaria de la zona resto fue de 40,3\% casi el doble de la reportada en la cabecera, 24,1\%. Pero hubo una situación más grave: casi la quinta parte de la población en el resto, 
$18,0 \%$, se ubicó en la categoría de indigente, frente a un 4,9\% de la población en la cabecera que se encontraba en esta condición. Ahora bien, analizando la pobreza multidimensional ${ }^{4}$, los resultados indican que el porcentaje de personas en situación de pobreza multidimensional fue de $40,0 \%$, esto es 4.314 .000 personas.

En el caso de las necesidades básicas insatisfechas (NBI), indicador que busca establecer las carencias que tienen los hogares, se observó que en la zona resto el 53,51\% de las personas está en condición de NBI y el $25,71 \%$ de personas en la miseria ${ }^{5}$.

Por otro lado, la realidad presentada por el Censo Nacional Agropecuario pone al descubierto las enormes brechas entre lo urbano y lo rural, de lo cual se desprenden estos altos niveles de pobreza y de concentración de la tierra en el campo colombiano. El sector agropecuario se ha caracterizado por un gran número de Unidades Productivas Agropecuarias (UPA) con poca área, en contraste con un número bastante reducido de grandes unidades de producción con mucha área disponible. El 69,9\% de las UPA tiene menos de cinco hectáreas, las cuales ocupan menos del $5 \%$ del área total censada. Tan solo $0,4 \%$ de las UPA tiene quinientas hectáreas o más, y son el 40,1\% del total de la superficie censada (Departamento Administrativo Nacional de Estadística, 2014).

4 El Índice de Pobreza Multidimensional (IPM) se construye con base en cinco dimensiones: condiciones educativas del hogar, condiciones de la niñez y la juventud, salud, trabajo, y acceso a los servicios públicos domiciliarios y condiciones de la vivienda. Estas 5 dimensiones involucran 15 indicadores, y son considerados pobres los hogares que tengan privación en por lo menos el $33 \%$ de los indicadores.

5 EVale la pena recordar que este indicador fija unas necesidades básicas definidas en 5 dimensiones: viviendas inadecuadas; viviendas con hacinamiento crítico; viviendas con servicios inadecuados; viviendas con alta dependencia económica y viviendas con niños en edad escolar que no asisten a la escuela. Así pues, se considera pobre un hogar que presenta al menos una de las anteriores privaciones, mientras que un hogar se encuentra en situación de miseria si incumple con dos o más de los criterios anteriormente descritos. 
Tabla 3. Indicadores sociales total nacional y por zonas 2013-2015

\begin{tabular}{|lcccccccccc|}
\hline & \multicolumn{3}{c}{ Concepto } & \multicolumn{1}{c}{ Nacional } & \multicolumn{3}{c}{ Cabecera } & \multicolumn{4}{c|}{$\begin{array}{c}\text { Centros poblados y } \\
\text { rural disperso }\end{array}$} \\
& 2013 & 2014 & 2015 & 2013 & 2014 & 2015 & 2013 & 2014 & 2015 \\
\hline $\begin{array}{l}\text { Tasa de pobreza } \\
\text { monetaria* }\end{array}$ & 30,6 & 28,5 & 27,8 & 26,9 & 24,6 & 24,1 & 42,8 & 41,4 & 40,3 \\
\hline $\begin{array}{l}\text { Tasa de pobreza } \\
\text { monetaria extrema* }\end{array}$ & 9,1 & 8,1 & 7,9 & 6,0 & 5,1 & 4,9 & 19,1 & 18,0 & 18,0 \\
\hline $\begin{array}{l}\text { Pobreza } \\
\text { multidimensional** }\end{array}$ & 24,8 & 21,9 & 20,2 & 18,5 & 15,4 & 14,4 & 45,9 & 44,1 & 40,0 \\
\hline $\begin{array}{l}\text { Coeficiente de Gini* } \\
\text { Pobreza por NBI*** }\end{array}$ & 0,539 & 0,538 & 0,522 & 0,517 & 0,514 & 0,498 & 0,446 & 0,463 & 0,454 \\
\hline & $27,78 \%$ & & & $19,66 \%$ & & & $53,51 \%$ & \\
\hline
\end{tabular}

Fuente:* Gran Encuesta Integrada de Hogares. DANE

** Encuesta Nacional de Calidad de Vida. DANE

***Censo General. DANE.

\section{Resultados de la Medición de Trabajo Decente para cabeceras y centros poblados y rural disperso 2013-2015}

\subsection{Dimensión 1: oportunidades de empleo}

En términos generales, esta dimensión contiene los indicadores que de forma más tradicional son usados para el análisis del mercado laboral. Estos indicadores permiten medir o valorar la cantidad de oportunidades de trabajo en las zonas del país, es decir, la medida en que todas las personas dispuestas a trabajar encuentran oportunidades de trabajo como punto básico de realización del derecho al trabajo y al trabajo decente. Es una buena aproximación para empezar a entender lo que significa el trabajo decente y es una dimensión que intenta mostrar en términos generales cómo evoluciona el mercado laboral de las cabeceras y los centros poblados y rural disperso. 


\subsubsection{Tasa de ocupación ${ }^{6}$}

En los tres años de análisis se encontró que en la zona resto del país la ocupación mostró una tendencia variable a diferencia de la tendencia creciente de la ocupación en las cabeceras. En la zona resto la tasa de ocupación se ubicó en 56,0\% ,3,8 puntos porcentuales pp por debajo de la reportada en la cabecera que fue de 59,8\% .

\section{Gráfico 2. Tasa de ocupación 2013-2015}

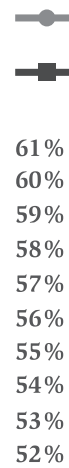

Cabecera

\section{Resto}

$\mathbf{6 1} \%$
$\mathbf{6 0} \%$
$59 \%$
$58 \%$
$57 \%$
$56 \%$
$\mathbf{5 5} \%$
$\mathbf{5 4} \%$
$\mathbf{5 3} \%$
$\mathbf{5 2} \%$

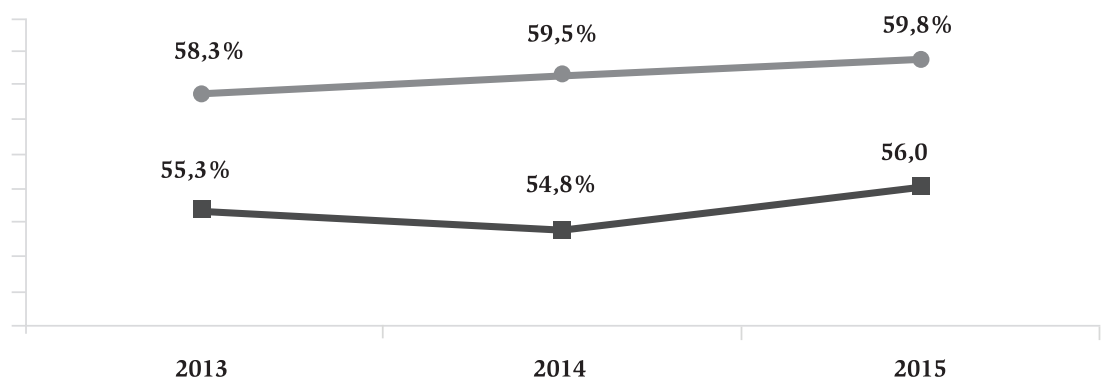

Fuente: Elaboración propia con base en DANE-GEIH, (2013-2015).

La ocupación por sexo mostró una enorme y marcada brecha entre hombres y mujeres en la zona resto más que en las cabeceras. En la primera zona la brecha de ocupación fue en promedio de $37 \mathrm{pp}$ entre unos y otras, mientras que en la segunda zona la brecha promedio fue de $18 \mathrm{pp}$. Estas brechas son evidencia de una discriminación en las oportunidades y un déficit de trabajo decente, que debe buscar reducirse hacia el futuro.

6 Las personas ocupadas son aquellas que durante el período de referencia (semana anterior a la aplicación de la encuesta) se encontraban en una de las siguientes situaciones: trabajó por lo menos una hora remunerada en la semana de referencia; no trabajaron en la semana de referencia, pero tenían un trabajo o fueron trabajadores familiares sin remuneración que trabajaron en la semana de referencia por lo menos 1 hora. 
Tabla 4. Tasa de ocupación desagregada por sexo 2013-2015

\begin{tabular}{|c|c|c|c|c|c|c|}
\hline Año & \multicolumn{2}{|c|}{2013} & \multicolumn{2}{|c|}{2014} & \multicolumn{2}{|c|}{2015} \\
\hline Según sexo & पె & p & पึ. & 帛 & पె & po \\
\hline Cabecera & $68,0 \%$ & $50,4 \%$ & $68,8 \%$ & $51,0 \%$ & $69,1 \%$ & $51,5 \%$ \\
\hline Resto & $73,3 \%$ & $34,9 \%$ & $72,3 \%$ & $34,9 \%$ & $73,3 \%$ & $36,3 \%$ \\
\hline
\end{tabular}

Fuente: Elaboración propia con base en DANE-GEIH, (2013-2015).

\subsubsection{Tasa de desempleo ${ }^{7}$}

La tasa de desempleo es quizá el indicador más conocido del mercado laboral y se ubica en el trabajo decente en la medida en que permite expresar el déficit de oportunidades de trabajo, dado en términos de las personas que buscan activamente un empleo. Entre las zonas consideradas, la zona resto presentó la tasa de desempleo más baja, con un promedio de $5,7 \%$ en los últimos años. Por su parte, la cabecera tuvo una tasa de desempleo en promedio de $10,2 \%$, incluso superior a la reportada para el total nacional. En 2015 había un total de 288.000 desempleados en la zona rural.

\section{Gráfico 3. Tasa de desempleo 2013-2015}

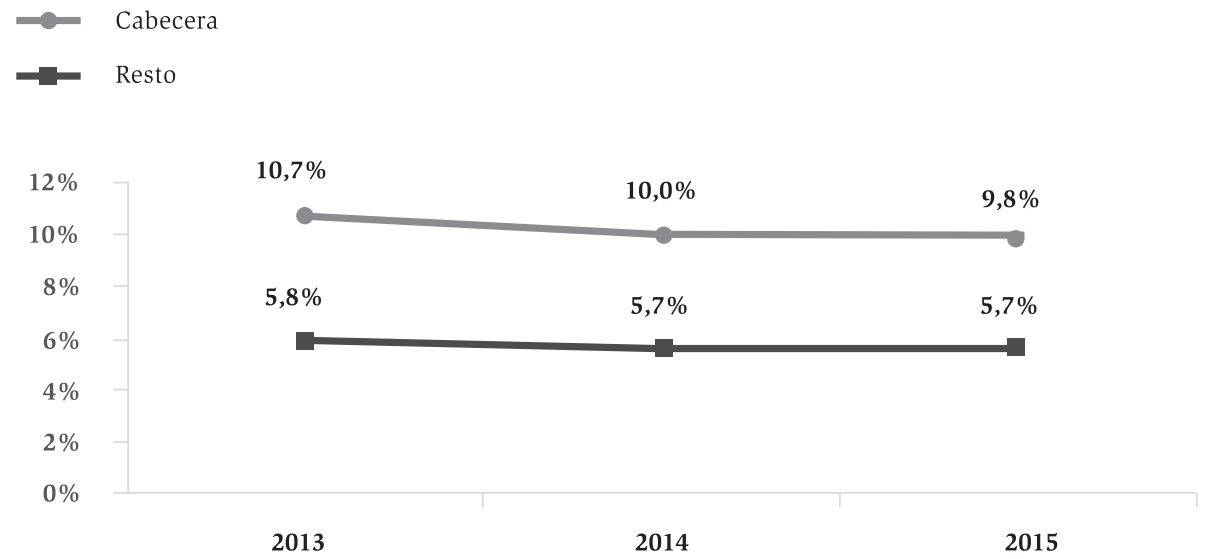

Fuente: Elaboración propia con base en DANE-GEIH, (2013-2015). 
Como se observa la tasa de desempleo en la zona resto ha sido inferior a la observada en la cabecera. Este resultado se debe a que los trabajadores del sector rural se ven obligados a aceptar o mantener trabajos de baja remuneración, debido a que no les es posible mantenerse desempleados en la medida en que sus salarios de reserva son relativamente bajos y, adicionalmente, los ingresos laborales representan aproximadamente el $82 \%$ de los ingresos totales del hogar (Santa María, Parad y Mujica, 2009).

Desagregando la población desempleada por sexo, es evidente que la mayor tasa de desempleo se presentó en las mujeres, en ambas zonas, la brecha con respecto a los hombres fue más amplia en la zona resto. Para el 2015, la tasa de desempleo de las mujeres se ubicó en 11,0\%, 7,8 (pp) superior a la reportada por los hombres: 3,2\% . Lo preocupante de esta situación es que los cambios que se han presentado de un año a otro en este indicador han sido marginales y no han logrado impactar en la disminución del desempleo femenino.

Tabla 5. Tasa de desempleo desagregada por sexo 2013-2015

\begin{tabular}{|c|c|c|c|c|c|c|}
\hline Año & \multicolumn{2}{|c|}{2013} & \multicolumn{2}{|c|}{2014} & \multicolumn{2}{|c|}{2015} \\
\hline Según sexo & ตึ & 舫 & ตึ & 禹 & חึ & 禹 \\
\hline Cabecera & $8,7 \%$ & $12,9 \%$ & $8,1 \%$ & $12,2 \%$ & $7,9 \%$ & $11,9 \%$ \\
\hline Resto & $3,4 \%$ & $11,3 \%$ & $3,5 \%$ & $10,5 \%$ & $3,2 \%$ & $11,0 \%$ \\
\hline
\end{tabular}

Fuente: Elaboración propia con base en DANE-GEIH, (2013-2015).

\subsubsection{Porcentaje de jóvenes que ni estudian ni trabajan (ninis)}

En América Latina, los jóvenes que ni estudian ni trabajan son comúnmente llamados “ninis”. Uno de cada cinco jóvenes del continente, que representan más de veinte millones de personas entre 15 y 24 años de edad, vive en estas condiciones (De Hoyos, Rogers y Székely, 2016). 
Colombia no es ajeno a este panorama, al contrario, al medir la tasa de ninis en el país, entendiendo que según la Ley 1622 de 2013 en el país un joven es quien se encuentra entre 14 y 28 años, los resultados son alarmantes, mientras que en el último año la tasa de jóvenes que ni estudiaban ni trabajan fue de $18,4 \%$ en la cabecera, en la zona resto el indicador se ubicó en $25,6 \%$, esto es, de cada cien jóvenes la cuarta parte se encontraba en esta condición.

\section{Gráfico 4. Porcentaje de jóvenes entre 14-28 años que no están estudiando ni trabajando}

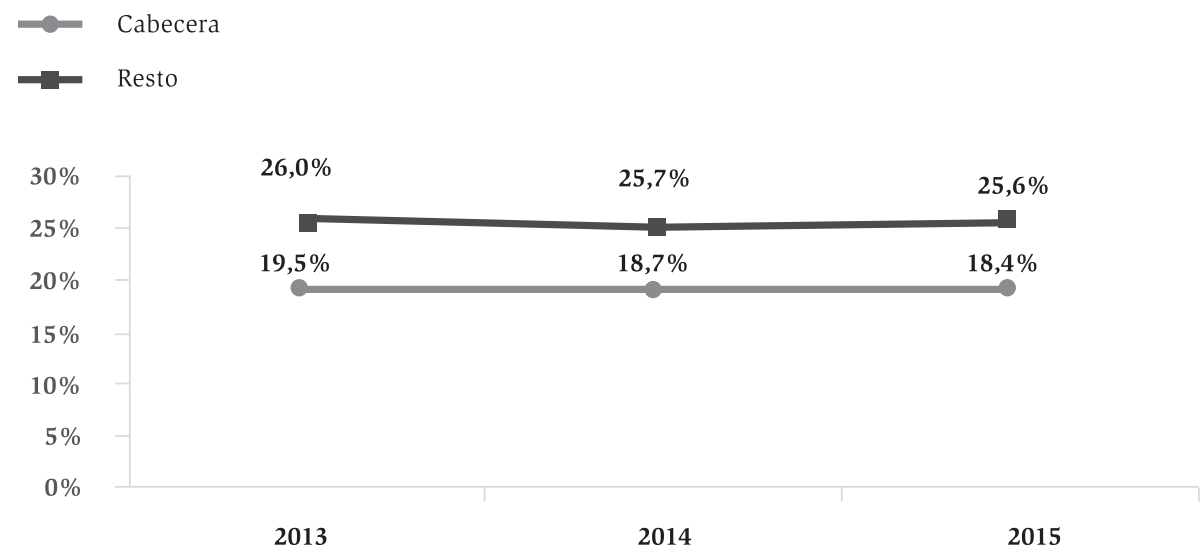

Fuente: Elaboración propia con base en DANE-GEIH, (2013-2015).

Para la mayor parte de los jóvenes, esta etapa del ciclo de vida se caracteriza por el cambio, la vulnerabilidad y el desarrollo de la autoestima y del sentido de pertenencia. Es probable que necesiten el apoyo de una supervisión y orientación especializadas. En resumen, para los jóvenes que están fuera del sistema educativo y del mercado laboral es especialmente difícil durante estos años afrontar los retos de la vida y desarrollar todo su potencial (Grogger, 1997; Jacob y Lefgren, 2003 citado por De Hoyos, Rogers y Székely, 2016). 
Además, esta problemática tiene un efecto adverso en los ingresos, ya que no solo reduce el producto total de la economía debido a una menor productividad laboral (el motor del crecimiento), sino que también obstaculiza la igualdad. Una incidencia de ninis más alta en los hogares pobres y vulnerables exacerba las desigualdades existentes, obstruye la movilidad social y la reducción de la pobreza a largo plazo (Ferreira y col., 2013; Vakis, Rigolini y Lucchetti, 2015 citado por De Hoyos, Rogers y Székely, 2016).

Analizando este indicador por sexo se encontró que mientras en la cabecera el porcentaje de mujeres ninis duplica al reportado por los hombres $(25,3 \%$ frente a $11,5 \%)$, en la zona resto el porcentaje de mujeres ninis casi quintuplica el reportado por los hombres $(43,8 \%$ frente a 9,0\%). Los factores de riesgo más importantes asociados a la condición de nini de las mujeres son el matrimonio precoz y el embarazo durante la adolescencia o incluso ambos.

Tabla 6. Porcentaje de jóvenes que no están estudiando ni trabajando, desagregado por sexo 2013-2015

\begin{tabular}{|c|c|c|c|c|c|c|}
\hline Año & \multicolumn{2}{|c|}{2013} & \multicolumn{2}{|c|}{2014} & \multicolumn{2}{|c|}{2015} \\
\hline Según sexo & पึ. & ఝ & पึ. & 我 & ตึ. & 我 \\
\hline Cabecera & $12,9 \%$ & $26,0 \%$ & $12,3 \%$ & $25,1 \%$ & $11,5 \%$ & $25,3 \%$ \\
\hline Resto & $9,2 \%$ & $44,4 \%$ & $9,6 \%$ & $43,5 \%$ & $9,0 \%$ & $43,8 \%$ \\
\hline
\end{tabular}

Fuente: Elaboración propia con base en DANE-GEIH, (2013-2015).

Este indicador debe convertirse en una referencia bajo el entendido de que si los jóvenes, especialmente las mujeres, no tienen acceso al mundo laboral o no logran cualificarse quedan expuestas a trabajos informales, muchas veces sin remuneración ni garantías, lo cual atenta contra el trabajo decente. Según la OIT las soluciones pasan por establecer políticas de empleo para jóvenes, otorgar créditos blandos, becas y otros incentivos para evitar o impedir la deserción escolar, conectar 
mejor a la educación con el empleo, estimular el espíritu emprendedor de los jóvenes y brindar incentivos y ayudas a madres jóvenes para que permanezcan en el estudio o en el mercado laboral.

\subsubsection{Tasa de desempleo juvenil ${ }^{8}$}

En los últimos tres años este indicador no ha presentado variaciones importantes en la zona resto y permaneció en 10,5\%. En la cabecera, el desempleo juvenil siempre ha sido superior y se ubicó en 16,4\% en el último año. La OIT ha insistido en la importancia de centrarse en los y las jóvenes debido a que el desempleo o las malas condiciones laborales para esta población amenazan las perspectivas laborales futuras de las personas, disminuye el ahorro y la demanda global en las economías y aumenta la exclusión y la inseguridad social.

\section{Gráfico 5. Tasa de desempleo juvenil 2013-2015}

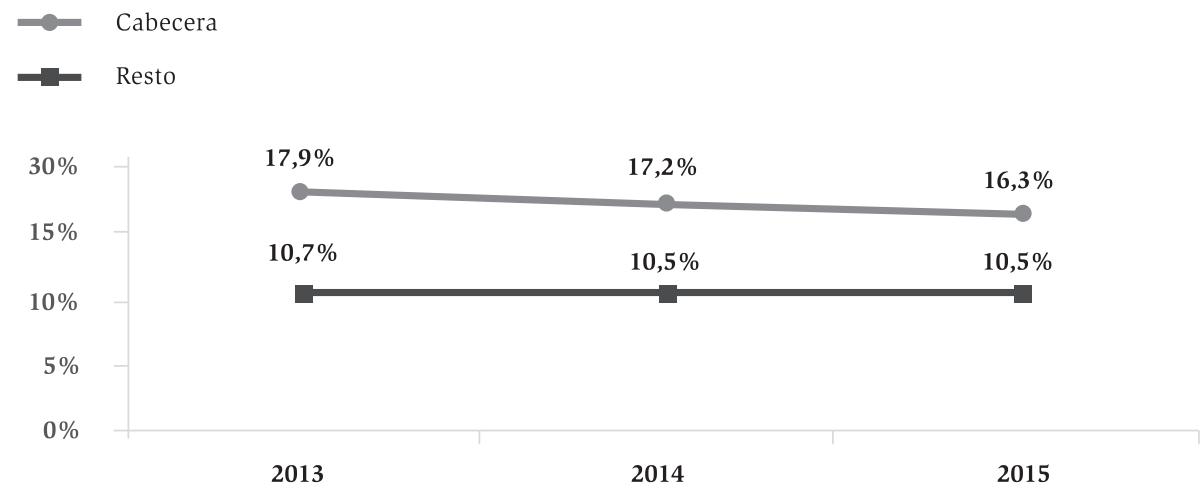

Fuente: Elaboración propia con base en DANE-GEIH, (2013-2015).

8 Corresponde al porcentaje de población de 14 a 28 años que se encuentran desempleados -o buscando empleo- con respecto a la fuerza laboral de 14 a 28 años. 
Por sexo, se evidencian enormes brechas entre la situación de las mujeres y la de los hombres en ambas zonas geográficas, pero es más compleja en la zona resto del país. Para esta última, la discriminación por sexo en cuanto a oportunidades de trabajo para los jóvenes se expresó en una diferencia de casi 14 pp desfavorable para ellas.

\section{Tabla 7. Tasa de desempleo juvenil (14 a 28 años) desagregada por sexo 2013-2015}

$\begin{array}{lllllll}\text { Año } & & & & & 2015 \\ \text { Según sexo } & 14,6 \% & 21,9 \% & 14,0 \% & 21,0 \% & 12,9 \% & 20,6 \% \\ \text { Cabecera } & 6,3 \% & 20,3 \% & 6,6 \% & 18,7 \% & 6,1 \% & 20,0 \% \\ \text { Resto } & 1013 & \end{array}$

Fuente: Elaboración propia con base en DANE-GEIH, (2013-2015).

Realizar constante seguimiento y verificación de este indicador podría aportar en la construcción de políticas o programas focalizados que favorezcan la inserción de los jóvenes al mundo laboral.

\subsubsection{Tasa de empleo informal por afiliación a seguridad social}

Corresponde al porcentaje de la población ocupada que no se encuentra afiliada al sistema de salud o a pensiones, lo cual produce una idea sobre el nivel de desprotección social de la población ocupada. Se aprecia una alta proporción de ocupados de la zona resto, que no tenían afiliación a dichos sistemas; de cada cien ocupados en esta zona, 87,6 estaba desprotegido. 


\section{Gráfico 6. Tasa de informalidad por afiliación a seguridad social 2013-2015}

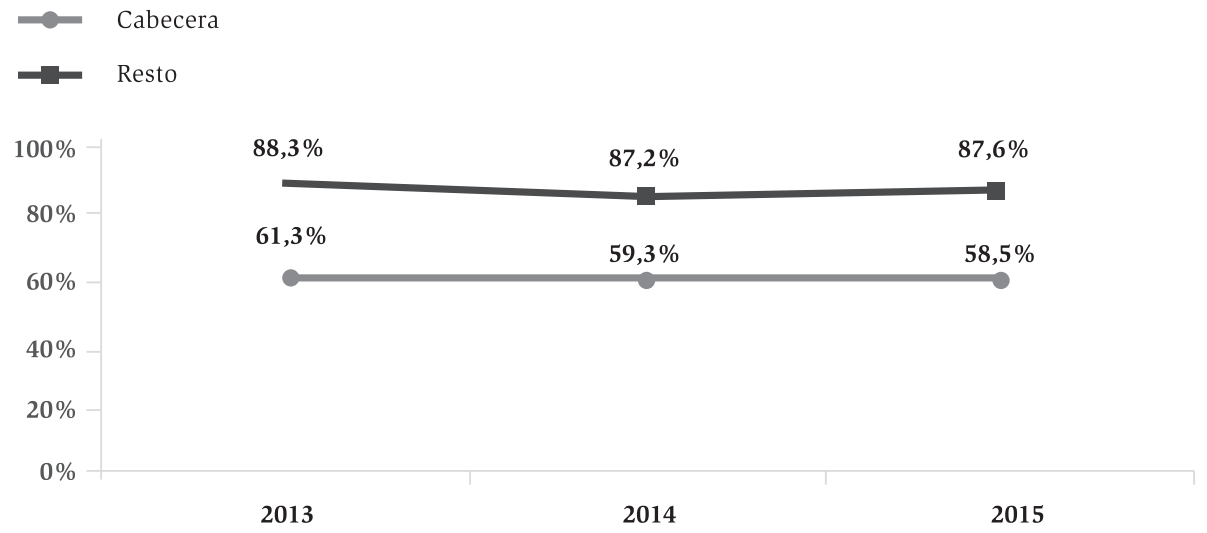

Fuente: Elaboración propia con base en DANE-GEIH, (2013-2015).

Los resultados evidencian una enorme brecha urbano-rural. El mercado laboral rural heterogéneo y altamente segmentado, con una proporción importante de personas ocupadas por cuenta propia, se refleja en estos niveles de desprotección. El empleo de las zonas rurales tiende a concentrarse en los ocupados por cuenta propia (51,6\% para el 2015), los cuales representan mayor proporción que los empleados asalariados. Esta estructura en el mercado laboral rural afecta la calidad del empleo, establece niveles insuficientes de ingresos y dificulta el acceso a los servicios de protección social (Merchán, 2014 citado por Departamento Nacional de Planeación, 2014).

Los resultados, según género indican que, si bien fueron las mujeres las que registraron un mayor nivel de desafiliación a los sistemas en la zona rural, la diferencia con respecto a los hombres no fue tan marcada como en indicadores anteriores. Para el 2015, la tasa de informalidad de las mujeres fue de $89,3 \%$ frente a $86,9 \%$ de los hombres. La desprotección social significa un riesgo alto en el deterioro de la calidad de vida y una condición desfavorable para el bienestar de los trabajadores, lo que desencadena pobreza. 
Tabla 8. Tasa de informalidad por afiliación a la seguridad social desagregada por sexo 2013-2015

\begin{tabular}{|c|c|c|c|c|c|c|}
\hline Año & \multicolumn{2}{|c|}{2013} & \multicolumn{2}{|c|}{2014} & \multicolumn{2}{|c|}{2015} \\
\hline Según sexo & |ึ. & 两 & ตึ. & 我 & पึ. & uึ \\
\hline Cabecera & $59,9 \%$ & $63,0 \%$ & $57,9 \%$ & $61,0 \%$ & $57,0 \%$ & $60,4 \%$ \\
\hline Resto & $87,3 \%$ & $90,7 \%$ & $86,3 \%$ & $89,4 \%$ & $86,9 \%$ & $89,3 \%$ \\
\hline
\end{tabular}

Fuente: Elaboración propia con base en DANE-GEIH, (2013-2015).

3.1.6. Proporción de los ocupados por cuenta propia y trabajadores familiares en la ocupación total

Este indicador busca ofrecer información sobre aquellos grupos de ocupaciones que representan riesgos para las oportunidades de empleo y para el trabajo decente, bajo la idea de que están expuestos a condiciones inestables en sus contratos o poseen condiciones precarias de trabajo. Según los resultados, seis de cada diez ocupados en la zona resto y cuatro de cada diez en la cabecera estaban laborando de manera independiente o eran trabajadores familiares.

\section{Gráfico 7. Proporción de ocupados cuenta propia y trabajadores familiares 2013-2015}
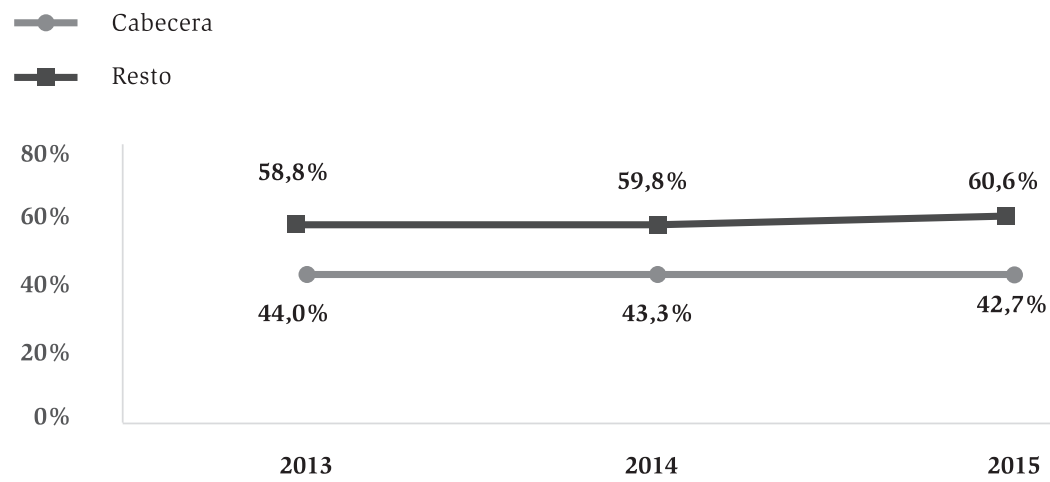

Fuente: Elaboración propia con base en DANE-GEIH, (2013-2015). 
En particular se encuentra que son los hogares en situación de pobreza extrema y de pobreza los que concentran la mayor parte de la población ocupada independiente o cuenta propia. De lo anterior, se infiere que es la población más vulnerable la que se encuentra más expuesta en la medida en que, por lo general, el empleo cuenta propia está relacionado con menores ingresos y mayor incertidumbre (Santa María, Parad y Mujica, 2009).

En la zona resto las mujeres fueron las que estuvieron más expuestas a este tipo de ocupaciones; la proporción de ocupadas cuentapropista y trabajadoras familiares permaneció invariable entre 2014-2015. Para este último año, de cada cien ocupadas, 67 estaban en ocupaciones expuestas a mayor riesgo económico y de cada cien ocupados 57,8 estaban en esta condición.

Tabla 9. Proporción de los ocupados por cuenta propia y trabajadores familiares en la ocupación total desagregada por sexo 2013-2015

\begin{tabular}{|c|c|c|c|c|c|c|}
\hline Año & \multicolumn{2}{|c|}{2013} & \multicolumn{2}{|c|}{2014} & \multicolumn{2}{|c|}{2015} \\
\hline Según sexo & $\overbrace{1}$ & m & ఝึ. & 更 & חึ & ֻึ \\
\hline Cabecera & $56,4 \%$ & $43,6 \%$ & $43,2 \%$ & $43,5 \%$ & $42,7 \%$ & $42,6 \%$ \\
\hline Resto & $55,1 \%$ & $67,7 \%$ & $56,6 \%$ & $67,1 \%$ & $57,8 \%$ & $67,1 \%$ \\
\hline
\end{tabular}

Fuente: Elaboración propia con base en DANE-GEIH, (2013-2015).

\subsection{Dimensión 2: ingresos suficientes y productividad}

Una parte de la discusión sobre la pobreza pasa por la importancia que representa el trabajo y los ingresos laborales dentro de los hogares, como una forma de acceder a mínimos vitales y a una vida digna. El trabajo remunerado es la principal fuente de ingresos para los hogares, por lo tanto, bajo esta premisa, es importante conocer el estado de los trabajadores, así como tener una idea sobre sus ingresos, con el fin de 
establecer programas o políticas que conduzcan siempre a mejores condiciones para ellos.

A diferencia de la dimensión anterior, que contiene indicadores usualmente utilizados dentro del análisis del mercado laboral, esta dimensión incorpora indicadores que son poco conocidos en el país.

\subsubsection{Tasa de trabajadores pobres}

La tasa de trabajadores pobres ofrece información sobre la relación empleo-pobreza, es decir, combina datos del mercado de trabajo ocupación- con datos de ingresos de los hogares, lo que permite medir el porcentaje de trabajadores que, a pesar de tener un empleo, viven en hogares identificados como pobres. Hay que aclarar que el concepto de pobreza aplicado en este indicador se da cuando el ingreso familiar per cápita es inferior a la línea de pobreza, por lo tanto, es un concepto que se aplica a los hogares y no a los individuos. Según estas consideraciones, una reducción de este indicador significa avances hacia el trabajo decente.

Los resultados son preocupantes no solo por el porcentaje tan alto de ocupados en hogares pobres en la zona rural, sino por la enorme brecha entre zonas. Para el 2015, el 41,9\% de los ocupados de la zona resto vivía en una hogar pobre, 17,3 pp por encima de lo reportado por los ocupados en la cabecera, $24,6 \%$. Una política social o laboral debería persistir sobre estrategias de redistribución del ingreso y mejoras en la productividad, con el fin de mejorar los ingresos reales de los hogares para atacar la pobreza y mejorar las condiciones hacia el trabajo decente en las zonas. 


\section{Gráfico 8. Tasa de ocupados pobres 2013-2015}

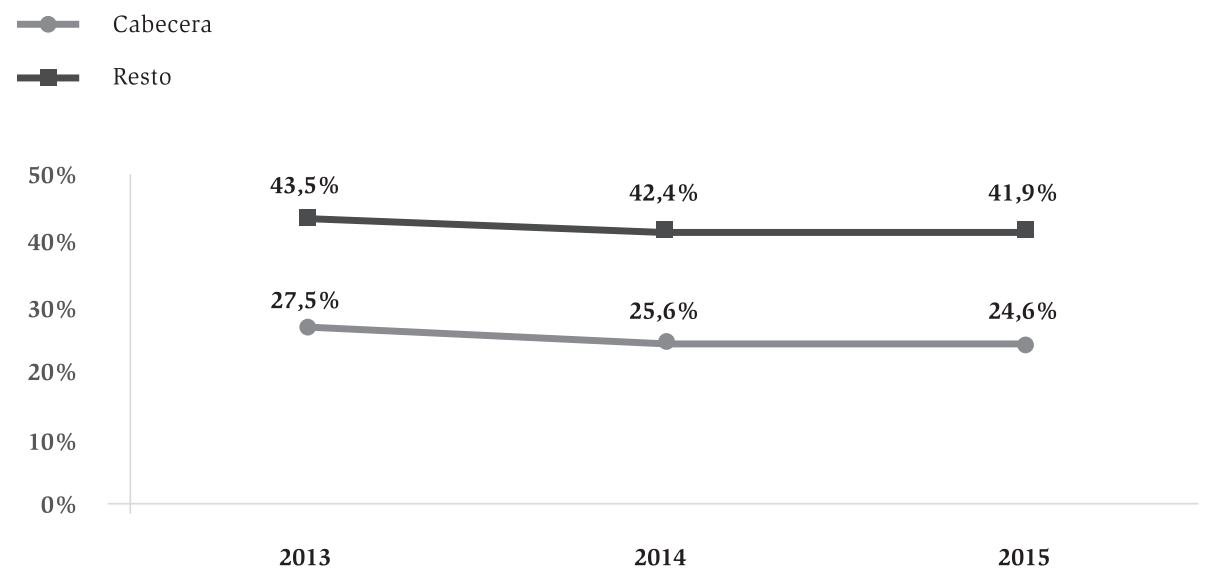

Fuente: Elaboración propia con base en DANE-GEIH, (2013-2015).

3.2.2. Tasa de asalariados con bajos ingresos (por debajo de $2 / 3$ de la mediana del ingreso por hora)

Este indicador, sumado al anterior, da pistas sobre qué tan pobres son los trabajadores según la distribución de los salarios por hora. En este sentido, cuanto más alto sea el indicador, existe un mayor número de asalariados que reciben una baja remuneración. En la zona resto el $36,4 \%$ de los asalariados contaba con bajos ingresos, a pesar de ser un porcentaje muy alto, este ha disminuido en más de 3 pp con respecto al año anterior. Por su parte, en la cabecera la mejora fue de 0,8 pp. La brecha entre zonas se ha cerrado levemente. 
Gráfico 9. Tasa de asalariados con bajos ingresos 2013-2015

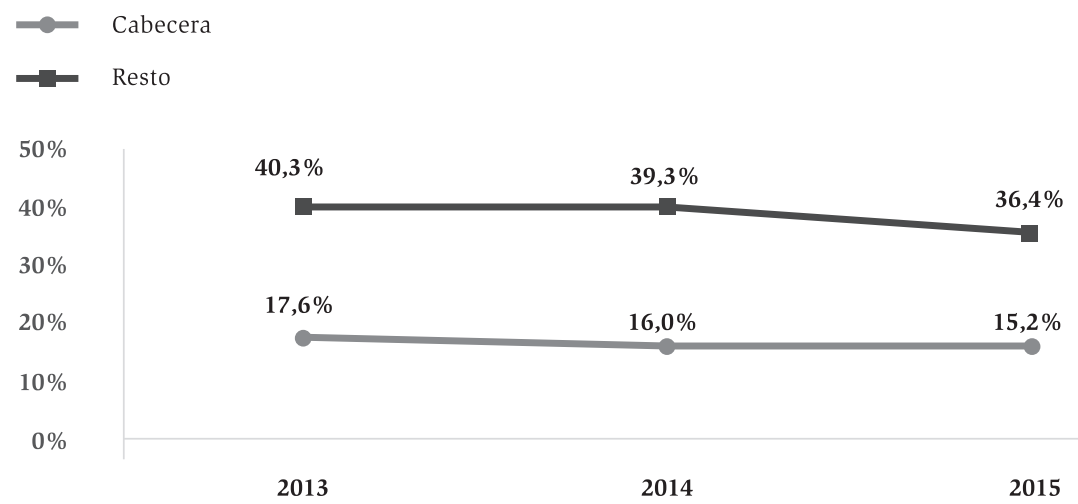

Fuente: Elaboración propia con base en DANE-GEIH, (2013-2015).

Para el 2015, en la zona resto, el 40,7\% de las mujeres asalariadas tenía bajos ingresos frente a un 34,9\% de los hombres. En la cabecera, la diferencia entre unas y otros fue más pequeña: 17,4\% frente a 13,4\% respectivamente.

Tabla 10. Tasa de asalariados con bajos ingresos (por debajo de $2 / 3$ de la mediana del ingreso por hora) desagregada por sexo 2013-2015

\begin{tabular}{|c|c|c|c|c|c|c|}
\hline Año & \multicolumn{2}{|c|}{2013} & \multicolumn{2}{|c|}{2014} & \multicolumn{2}{|c|}{2015} \\
\hline Según sexo & שึ & $\stackrel{n}{n}$ & $\prod_{0}^{0}$ & $\underset{n}{n}$ & మ․ & a \\
\hline Cabecera & $16,4 \%$ & $19,0 \%$ & $14,3 \%$ & $18,0 \%$ & $13,4 \%$ & $17,4 \%$ \\
\hline Resto & $38,6 \%$ & $46,1 \%$ & $37,6 \%$ & $44,5 \%$ & $34,9 \%$ & $40,7 \%$ \\
\hline
\end{tabular}

Fuente: Elaboración propia con base en DANE-GEIH, (2013-2015).

\subsubsection{Salario promedio real}

El salario promedio real se incluye en la medición pero debe ser interpretado con la debida limitación que representa, dado que la información utilizada —GEIH DANE- captura ingresos brutos, mas no netos; por 
lo tanto, se restringe el análisis sobre capacidad de compra de los hogares ${ }^{9}$. Para el 2015 el salario promedio de la zona resto fue el 56,6\% del salario promedio de la cabecera (\$593.527 versus $\$ 1.049 .060)$ mientras que en 2014 la proporción fue de 54,6\% (601.343 versus 1.101.169).

\section{Gráfico 10. Salario promedio real 2013-2015}

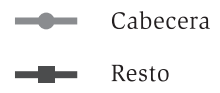

1.500 .000

1.000 .000

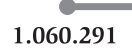

1.101 .169

1.049 .060

500.000

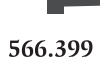

601.343

593.527

0

2013

2014

2015

Fuente: Elaboración propia con base en DANE-GEIH, (2013-2015).

\subsection{Dimensión 3: tiempo de Trabajo Decente (TD)}

Esta dimensión es la que refleja la situación de los trabajadores en términos de los tiempos en el trabajo y es producto de una preocupación sobre la posibilidad de que los trabajadores laboren más horas de las permitidas o consideren que están subutilizados bajo consideraciones de tiempo.

Aunque en el país es usual que el tiempo laboral no sea un aspecto discutido dentro del proceso de contratación, sino simplemente se le informa al trabajador su horario, en ocasiones se presentan casos en 
donde a los trabajadores ni siquiera se les respeta dicho horario. Esta dimensión pone de relieve la importancia de los acuerdos y los arreglos en el trabajo, así como el diálogo social, que son temas sobre los cuales la OIT hace énfasis.

\subsubsection{Tasa de ocupados en tiempo de trabajo excesivo}

Este indicador identifica los excesos en el trabajo medido por el mayor tiempo que se dedica a él, lo cual tiene incidencia sobre los trabajadores desde diversos ámbitos: salud, tiempo familiar, relaciones sociales, descanso, recreación, entre otros. El indicador muestra el porcentaje de los ocupados que laboran en la semana más de las cuarenta y ocho horas legales. Para la zona resto, el indicador disminuyó en 2,6 pp de un año a otro, al pasar de $27,5 \%$ a $24,9 \%$, mientras que en la cabecera el indicador solo disminuyó en un pp, pues pasó de 32,1\% a 31,1\% ocupados en horarios excesivos.

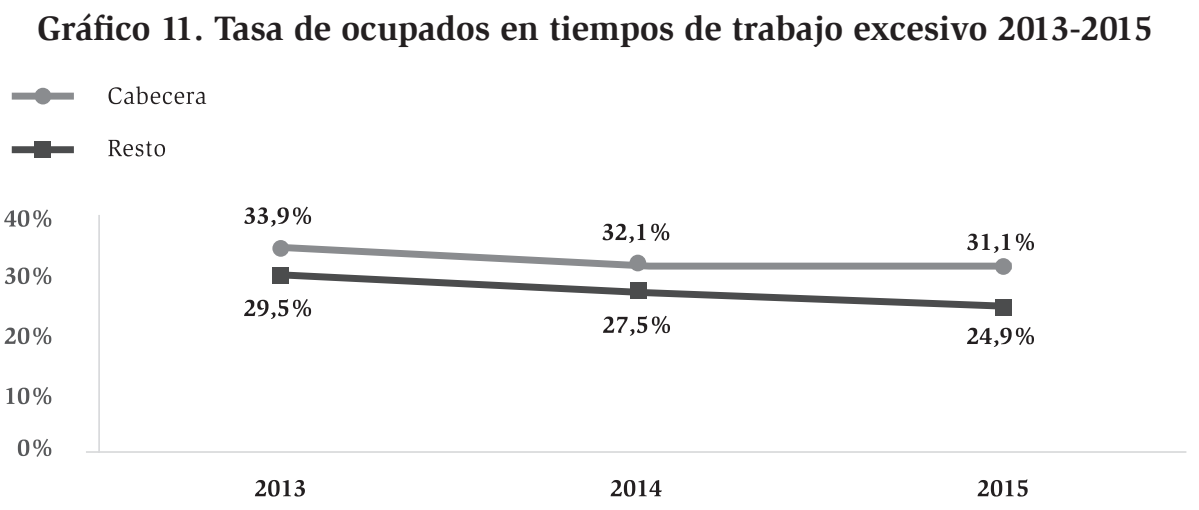

Fuente: Elaboración propia con base en DANE-GEIH, (2013-2015). 
3.3.2. Ocupados por horas de trabajo a la semana

Los ocupados por horas de trabajo muestra la participación porcentual de los ocupados, según el rango de horas trabajadas a la semana, para ello, se tienen como base las cuarenta y ocho horas, tiempo límite en Colombia. En la zona resto los resultados dejan ver que cerca de un $75 \%$ de los ocupados trabajó hasta cuarenta y ocho horas, de los cuales $32,6 \%$ trabajó menos de cuarenta horas, $26,2 \%$ trabajó entre cuarenta y cuarenta y siete horas, mientras que $16,3 \%$ trabajó cuarenta y ocho horas. De acuerdo con Pineda (2013), este indicador proporciona información indirecta sobre el tiempo que los trabajadores dedican a actividades diferentes del trabajo como descanso, vida familiar, trabajo doméstico, entre otros.

\section{Gráfico 12. Distribución porcentual de los ocupados según jornada de trabajo zona resto 2013-2015}

2015
2014
2013

Más de 48 horas

48 horas

Entre 41 y 47 horas

40 horas

Menos de 40 horas

0
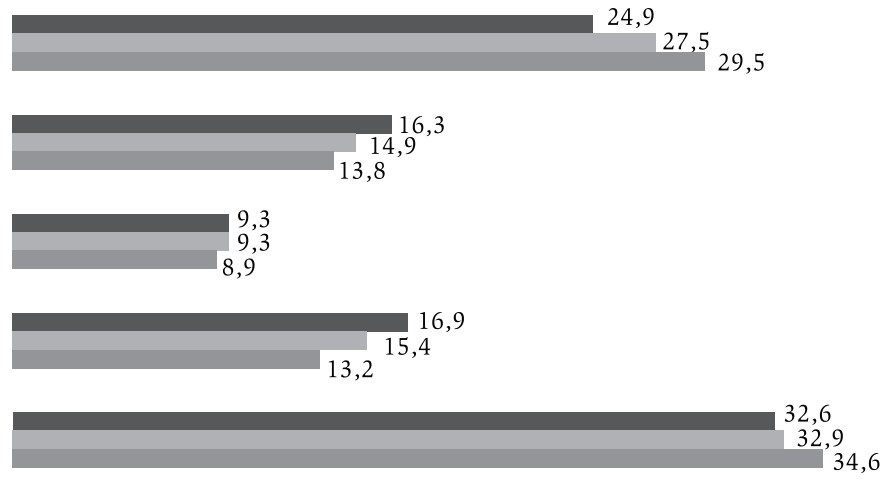

$5 \quad 10$

15

20

15

30

35

40 


\subsection{Dimensión 4: conciliación del trabajo, la vida fami- liar y la vida personal}

La idea de esta dimensión es contar con información capaz de poner de relieve las relaciones entre el trabajo y la vida familiar y personal de los trabajadores, haciendo análisis diferenciado por sexo, ya que existe una preocupación particular sobre las mujeres, quienes parecen ejercer en mayor proporción actividades no remuneradas relacionadas con el cuidado.

\subsubsection{Tasa de tiempo de trabajo no remunerado frente al remunerado}

El propósito del indicador es mostrar las cargas de tiempo de trabajo entre aquellas actividades remuneradas y las que no lo son. La premisa sobre la cual se parte apunta a que los trabajadores dedican parte de su tiempo a actividades no remuneradas en el hogar y que esta carga impide aceptar otras demandas de trabajo remuneradas fuera del hogar, lo que tiene incidencia en la productividad, los ascensos laborales, la salud, entre otros aspectos. En otras palabras, y de acuerdo con Pineda (2013), "este indicador mide la relación de horas promedio semanales que la persona le dedica a actividades no remuneradas con respecto a las horas semanales que dedica a actividades remuneradas".

En la zona resto se apreció una alta tasa de tiempo no remunerado frente al remunerado, para 2015 el $97 \%$ del tiempo de los trabajadores fue dedicado a actividades no remuneradas. Estos resultados son el reflejo de actividades desarrolladas en el hogar como cuidado de ancianos, preparación de alimentos, limpieza del hogar, entre otras. 


\section{Gráfico 13. Tasa de tiempo de trabajo no remunerado frente al remunerado 2013-2015}

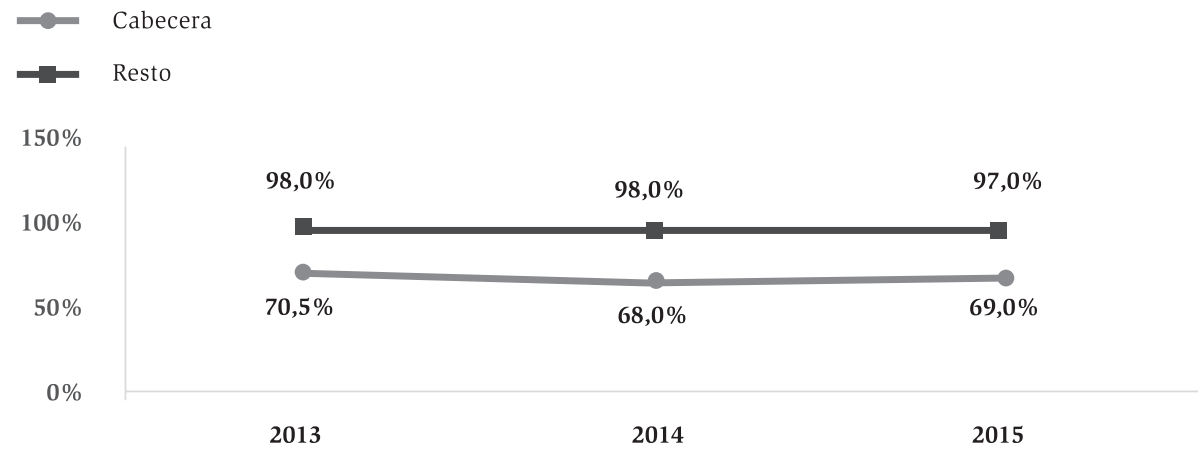

Fuente: Elaboración propia con base en DANE-GEIH, (2013-2015).

Por género, los resultados reflejan un significativo desbalance que afecta más a las mujeres. En 2015 los hombres dedicaron el 29\% del tiempo a actividades no remuneradas, mientras que las mujeres dedicaron el $314 \%$. De acuerdo con planteamientos de la OIT sobre este tema, un indicador alto significa dificultades para conciliar la relación trabajofamilia, lo que podría conducir a la aparición de conflictos que lesionan una u otra relación.

Tabla 11. Tasa de tiempo de trabajo no remunerado frente al remunerado desagregada por sexo 2013-2015

\begin{tabular}{|c|c|c|c|c|c|c|}
\hline Año & \multicolumn{2}{|c|}{2013} & \multicolumn{2}{|c|}{2014} & \multicolumn{2}{|c|}{2015} \\
\hline Según sexo & |ִ & 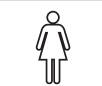 & ఝ̊ & $\stackrel{n}{n}$ & ఝ̊ & 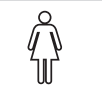 \\
\hline Cabecera & $24,2 \%$ & $140,0 \%$ & $24,0 \%$ & $134,0 \%$ & $24,0 \%$ & $135,0 \%$ \\
\hline Resto & $30,0 \%$ & $336,0 \%$ & $31,0 \%$ & $325,0 \%$ & $29,0 \%$ & $314,0 \%$ \\
\hline
\end{tabular}

Fuente: Elaboración propia con base en DANE-GEIH, (2013-2015). 
Si se cruza esta información con la reportada por el DANE en la Encuesta Nacional de Usos del Tiempo (ENUT) se evidencia que, al analizar la diferencia entre los contextos urbano y rural para las actividades no remuneradas de cuidado, la brecha de género se amplía en el segundo caso y que el tiempo dedicado a dichas actividades se incrementa sustancialmente en el caso de las mujeres. Así las cosas, mientras en las cabeceras las mujeres dedicaron 4,35 más horas que los hombres a actividades de cuidado (6,35 horas frente a 2 respectivamente), en contextos rurales dedicaron 5,44 más horas $(7,37$ horas frente a 1,53$)$; de este modo, el tiempo que las mujeres dedican a estas actividades en las zonas urbanas triplica el de los hombres, y en la ruralidad lo cuadriplica (Osorio y Tangarife, 2015).

\subsection{Dimensión 5: trabajo que debería abolirse}

En el mundo existen ciertos tipos de trabajo que deben abolirse, como lo son el trabajo infantil y el trabajo forzoso. El trabajo que debe abolirse es el trabajo infantil que corresponde a alguna de las siguientes categorías (Organización Internacional del Trabajo, 2002):

- Un trabajo realizado por un niño que no alcance la edad mínima especificada para el tipo de trabajo de que se trate (según determine la legislación nacional, de acuerdo con normas internacionalmente aceptadas), y que, por consiguiente, impida probablemente la educación y el pleno desarrollo del niño.

- Un trabajo que ponga en peligro el bienestar físico, mental o moral del niño, ya sea por su propia naturaleza o por las condiciones en que se realiza, y que se denomina trabajo peligroso.

- Las formas incuestionablemente peores de trabajo infantil, que internacionalmente se definen como esclavitud, trata de personas, servidumbre por deudas y otras formas de trabajo forzoso, reclutamiento forzoso de niños para utilizarlos en conflictos armados, prostitución y pornografía, y actividades ilícitas. 
Medir el trabajo que debería abolirse es necesario para determinar sus características e incidencia para luego realizar y ejecutar programas adecuados para erradicarlo.

\subsubsection{Tasa de Trabajo Infantil (TTI)}

La tasa de trabajo infantil presenta dos formas de medición, la primera corresponde a los datos provenientes de la GEIH que toma como base los niños, niñas y adolescentes (NNA) entre los diez y los diecisiete años, pero excluye a la franja de cinco a nueve años de edad, periodo que el indicador debe tener en cuenta. La segunda forma corresponde a la tasa de trabajo infantil que estima el DANE a través del módulo específico de trabajo infantil, el cual considera a los niños, niñas y adolescentes entre los cinco y diecisiete años de edad que trabajan en relación con las personas de la misma edad, este indicador está disponible para los trimestres octubre -diciembre desde 2013 a 2015.

En el caso de la estimación a través de la GEIH se encontró que la tasa de trabajo infantil para la zona resto se ubicó en 19,2\% en el 2013, y presenta una leve variación en 2014 para luego ubicarse en 17,7\% en 2015. En la cabecera la TTI fue inferior y no mostró variaciones significativas, se ubicó en 8,3\% para el último año. 
Gráfico 14. Tasa de trabajo infantil -niños, niñas y adolescentes entre 10-17 años- 2013-2015

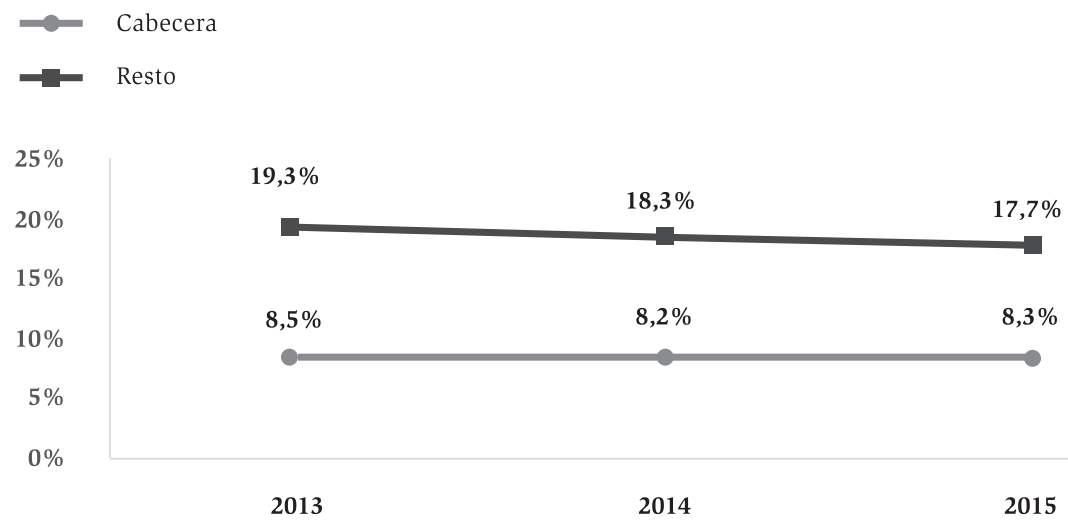

Fuente: Elaboración propia con base en DANE-GEIH, (2013-2015).

Al desagregar la tasa de trabajo infantil por sexo, tanto para la zona resto como para la cabecera, la TTI de los niños fue superior a la reportada por las niñas. En la zona resto la TTI de los niños fue de 27,1\% en 2013 y terminó en 2015 con una tasa de 23,9\%. En el caso de las niñas no hubo cambios significativos y la TTI se ubicó en 9,9\% al igual que en 2013. En la cabecera TTI de los niños estuvo por encima del indicador de las niñas en más de 3 pp durante los años de análisis y se ubicó en 2015 en $9,7 \%$ y $6,7 \%$, respectivamente.

Tabla 12. Tasa de trabajo infantil -niños, niñas y adolescentes entre 10-17 años- 2013-2015

\begin{tabular}{|c|c|c|c|c|c|c|}
\hline Año & \multicolumn{2}{|c|}{2013} & \multicolumn{2}{|c|}{2014} & \multicolumn{2}{|c|}{2015} \\
\hline Según sexo & 间 & $\stackrel{n}{n}$ & 象 & $\stackrel{n}{a}$ & ח. & 象 \\
\hline Cabecera & $10,4 \%$ & $6,6 \%$ & $9,6 \%$ & $6,6 \%$ & $9,7 \%$ & $6,7 \%$ \\
\hline Resto & $27,1 \%$ & $9,9 \%$ & $24,8 \%$ & $10,2 \%$ & $23,9 \%$ & $9,9 \%$ \\
\hline
\end{tabular}

Fuente: Elaboración propia con base en DANE-GEIH, (2013-2015). 
Ahora bien, analizando la tasa de trabajo infantil a través del módulo que realiza el DANE directamente, se encontró que para el cuarto trimestre de 2013 esta tasa se ubicó en 15,8\%, y culminó en 2015 en $15,6 \%$. Es importante resaltar que en comparación con la cabecera, la TTI de la zona resto ha sido superior en casi el doble en los tres años de análisis y terminó en 2015 con una diferencia de 8,9 pp.

\section{Gráfico 15. Tasa de trabajo infantil -niños, niñas y adolescentes entre 10-17 años- 2013-2015}

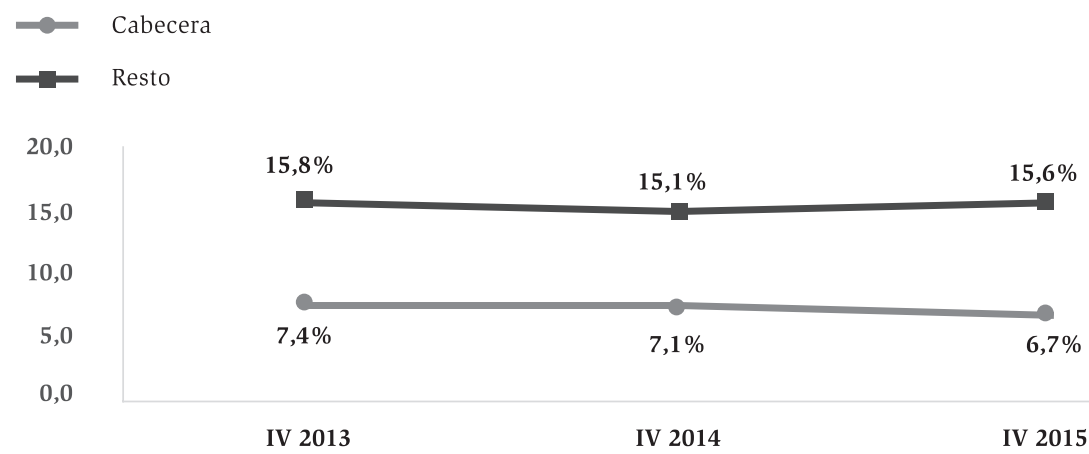

Fuente: Elaboración propia con base en DANE-GEIH, (2013-2015).

\subsubsection{Tasa de Trabajo Infantil Ampliada (TTIA)}

Este indicador corresponde a los niños, niñas y adolescentes que trabajan, más los que se dedican por quince horas y más a oficios del hogar durante la semana de referencia, y no trabajan, con respecto a la población total en este grupo de edad. De acuerdo con las recomendaciones del Programa Internacional para la Erradicación del Trabajo Infantil de la OIT, cuando el tiempo dedicado por los niños, niñas y adolescentes a oficios del hogar es de quince y más horas semanales, se incluye como trabajo adicional. Los oficios del hogar considerados son lavar, planchar, cocinar, cuidar niños pequeños o personas enfermas, atender la 
huerta casera, cría y cuidado de animales, hacer mandados o mercados, limpieza y mantenimiento del hogar, entre otros.

Los resultados a través de la GEIH indican que en la zona resto la TTIA se ubicó en 10,7\% para el último año, lo que muestra una disminución marginal con respecto a 2013 cuando fue de $11,1 \%$. Por su parte, la TTIA en la cabecera se ubicó en 4,9\%, 5,8 pp por debajo de la reportada en la zona resto.

\section{Gráfico 16. Tasa de trabajo infantil ampliada -niños, niñas y} adolescentes entre 10-17 años- 2013-2015
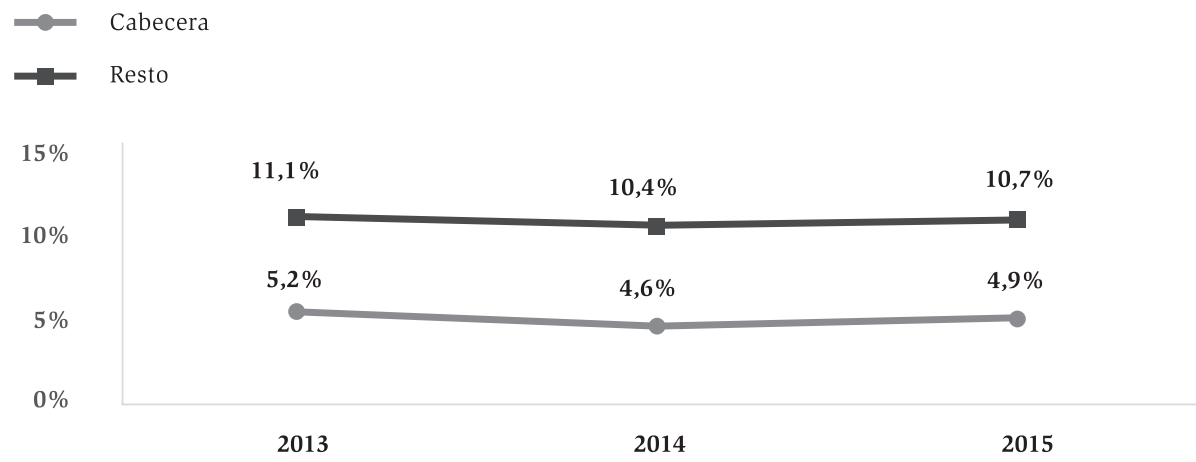

Fuente: Elaboración propia con base en DANE-GEIH, (2013-2015).

Por sexo, la TTIA presentó la misma tendencia que la TTI, fueron los niños los que mayores tasas reportaron. En 2015 se encontró que en la zona resto la TTIA de los niños fue de $15,8 \%$ y la de las niñas de $4,2 \%$, con una brecha entre unos y otras de más de $11 \mathrm{pp}$. En la cabecera la diferencia fue de casi 3 pp, para el último año la TTIA de los niños fue de $6,2 \%$ y la de las niñas de $3,4 \%$. 
Tabla 13. Tasa de Trabajo Infantil Ampliada (TTIA) desagregada por sexo 2013-2015

\begin{tabular}{|c|c|c|c|c|c|c|}
\hline Año & \multicolumn{2}{|c|}{2013} & \multicolumn{2}{|c|}{2014} & \multicolumn{2}{|c|}{2015} \\
\hline Según sexo & 舟 & $\stackrel{n}{n}$ & ఝ̊ & य & ๓̊ & $\stackrel{n}{a}$ \\
\hline Cabecera & $8,7 \%$ & $12,9 \%$ & $8,1 \%$ & $12,2 \%$ & $7,9 \%$ & $11,9 \%$ \\
\hline Resto & $3,4 \%$ & $11,3 \%$ & $3,5 \%$ & $10,5 \%$ & $3,2 \%$ & $11,0 \%$ \\
\hline
\end{tabular}

Fuente: Elaboración propia con base en DANE-GEIH, (2013-2015).

Cuando se analizó la TTIA por el módulo específico, se encontró que para el cuarto trimestre de 2015 la TTIA de la zona resto fue de $22,4 \%$, más del doble de la reportada en la cabecera donde llegó a 11,0\%.

\section{Gráfico 17. Tasa de trabajo infantil ampliada -niños, niñas y adolescentes entre 5-17 años- 2013-2015}

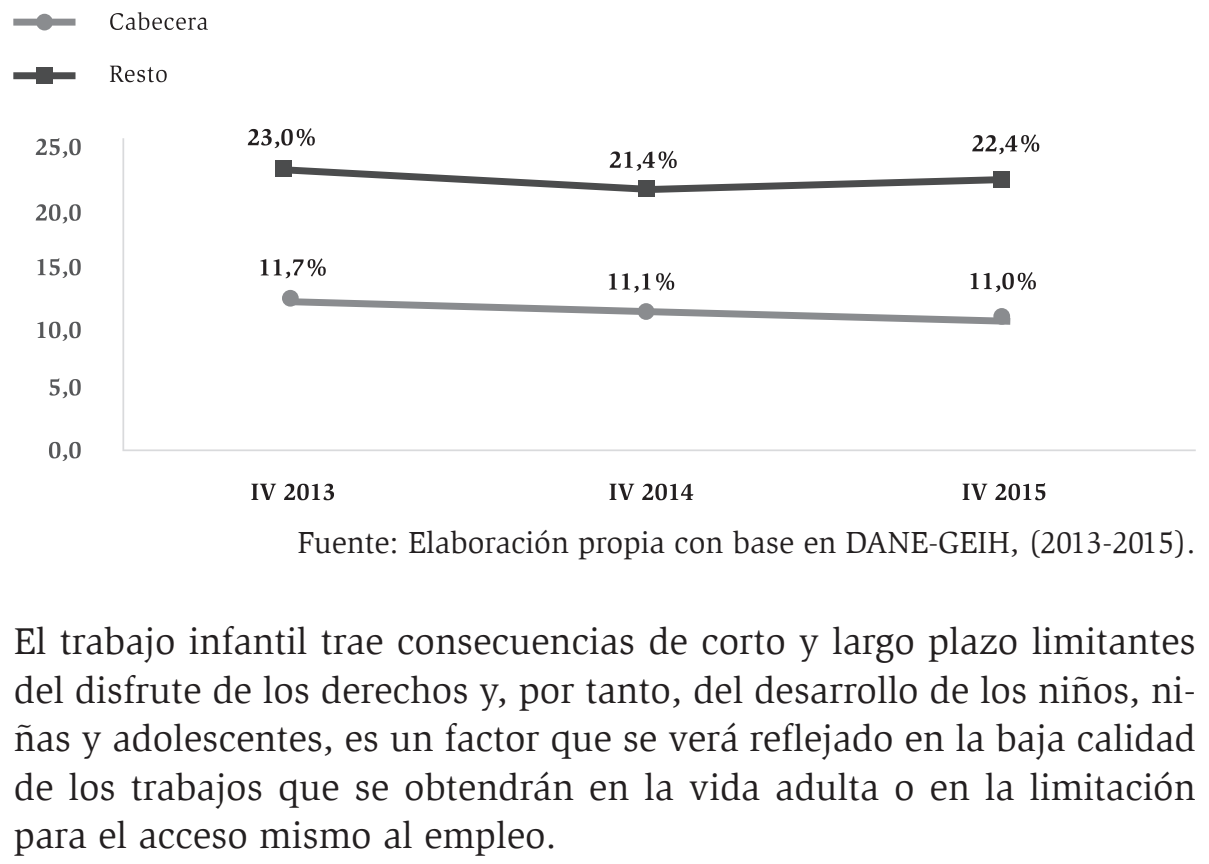


El trabajo infantil aleja a los niños y a las niñas de la educación. En 2015, en la zona resto, el 36,7\% de quienes trabajaban no asistían a una institución educativa, el resto combinaba educación y trabajo, una situación que redunda en bajo nivel académico y al final en la deserción escolar, en tanto la escuela no les proporciona los beneficios de contar con ingresos o apoyo para la obtención de los ingresos familiares. En este sentido, la principal razón por la que los niños, niñas y adolescentes trabajaron se relacionaba con que debían participar en la actividad económica de la familia (43,2\% del total de ocupados).

\subsection{Dimensión 6: estabilidad y seguridad del trabajo}

De acuerdo con OIT, la dimensión estabilidad y seguridad del trabajo permite diferenciar a los trabajadores cuyos trabajos se caracterizan por un grado de permanencia relativa de aquellos cuyos trabajos no ofrecen expectativas de una relación de larga duración. Los indicadores se dan en términos de la participación del empleo en categorías de trabajo inestable. El primer indicador para esta dimensión es el trabajo precario que se centra en la duración de los contratos laborales o la posibilidad de un despido rápido; el segundo se refiere a la antigüedad en el trabajo, que analiza la duración de tiempo en la que los trabajadores han estado en su trabajo actual, sin importar la duración del contrato.

\subsubsection{Tasa de empleo precario}

La tasa de empleo precario considera a los trabajadores sin contrato o con contrato a término fijo, o vinculados a través de Empresas de Servicios Temporales, Cooperativas de Trabajo Asociado o Empresas Asociativas de Trabajo, sobre el total de ocupados. En la zona resto casi la totalidad de los ocupados se encontraba en un empleo precario, 91,2\% para el 2015, sin presentar variaciones destacadas en el período de análisis. En la cabecera el 70,0\% de los ocupados estaba en un empleo precario, disminuyendo en más de 2 pp con respecto a 2013. 


\section{Gráfico 18. Tasa de empleo precario 2013-2015}

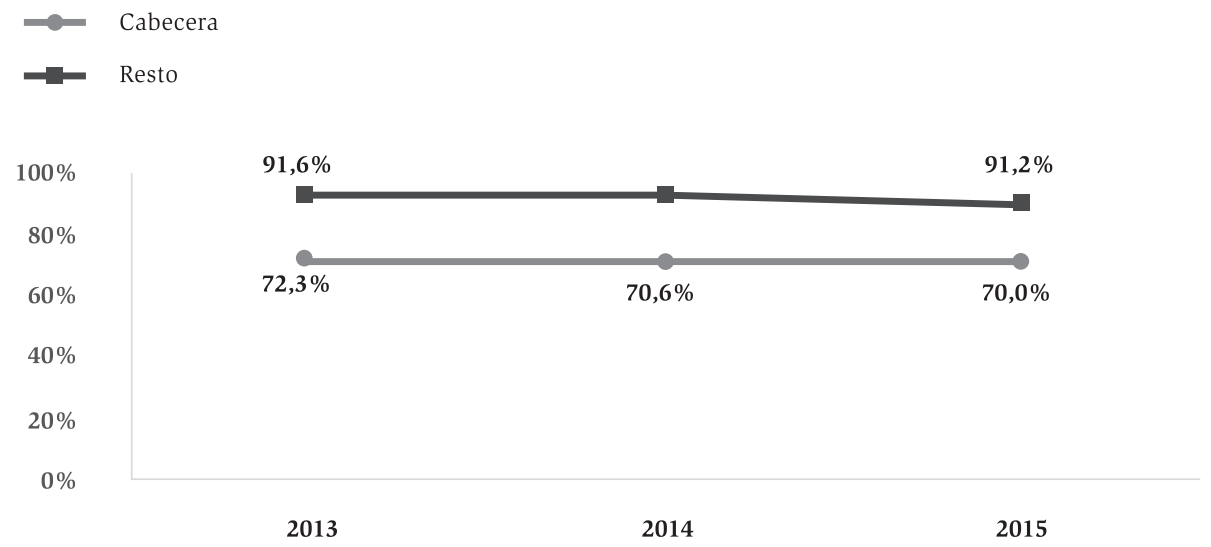

Fuente: Elaboración propia con base en DANE-GEIH, (2013-2015).

Tanto hombres como mujeres registraron altas tasas de empleo precario; sin embargo, fueron ellas las que reportaron tasas mayores. Para el 2015, en la zona resto, de cada 100 mujeres ocupadas, 93 se encontraban en un empleo precario, mientras que en el caso de los hombres de cada 100 ocupados 90 estaban en esa situación. En las cabeceras la proporción fue de 71 frente a 69 respectivamente.

La anterior situación se sustenta en el hecho de que, si bien las mujeres han incrementado su participación en el mercado laboral, son ellas las que más altas tasas de informalidad reportan, además laboran en condiciones estructurales de precariedad y discriminación fundadas en estereotipos de género. 
Tabla 14. Tasa de empleo precario desagregado por sexo 2013-2015

\begin{tabular}{|c|c|c|c|c|c|c|}
\hline Año & \multicolumn{2}{|c|}{2013} & \multicolumn{2}{|c|}{2014} & \multicolumn{2}{|c|}{2015} \\
\hline Según sexo & पึ. & 為 & ตึ. & ఝึ & חึ & 為 \\
\hline Cabecera & $72,1 \%$ & $72,7 \%$ & $70,1 \%$ & $71,4 \%$ & $69,3 \%$ & $71,0 \%$ \\
\hline Resto & $90,5 \%$ & $93,8 \%$ & $90,6 \%$ & $93,2 \%$ & $90,2 \%$ & $93,2 \%$ \\
\hline
\end{tabular}

Fuente: Elaboración propia con base en DANE-GEIH, (2013-2015).

\subsubsection{Antigüedad en el trabajo}

La antigüedad en el trabajo puede mirarse de manera positiva si corresponde a la estabilidad en un trabajo en condiciones decentes, esto es, con ingresos adecuados, acceso a la seguridad social integral, garantías reales para participar en el diálogo social, entre otras. Sin embargo, el indicador debe desagregarse por posiciones ocupacionales con miras a establecer la diferencia en la antigüedad para los trabajadores asalariados y los no asalariados.

En 2013, los trabajadores de la zona resto tenían un promedio de antigüedad en sus trabajos de 8,3 años (100 meses) tiempo similar al reportado en 2015 donde la diferencia fue de dos meses más de un año a otro. Con respecto a la cabecera los resultados indican que para el 2013 la antigüedad de los trabajadores en sus trabajos era de 5,9 años (70,8 meses) para terminar en 2015 con un tiempo de 5,8 años (69,9 meses). 


\section{Gráfico 19. Antigüedad en el trabajo -en meses- 2013-2015}

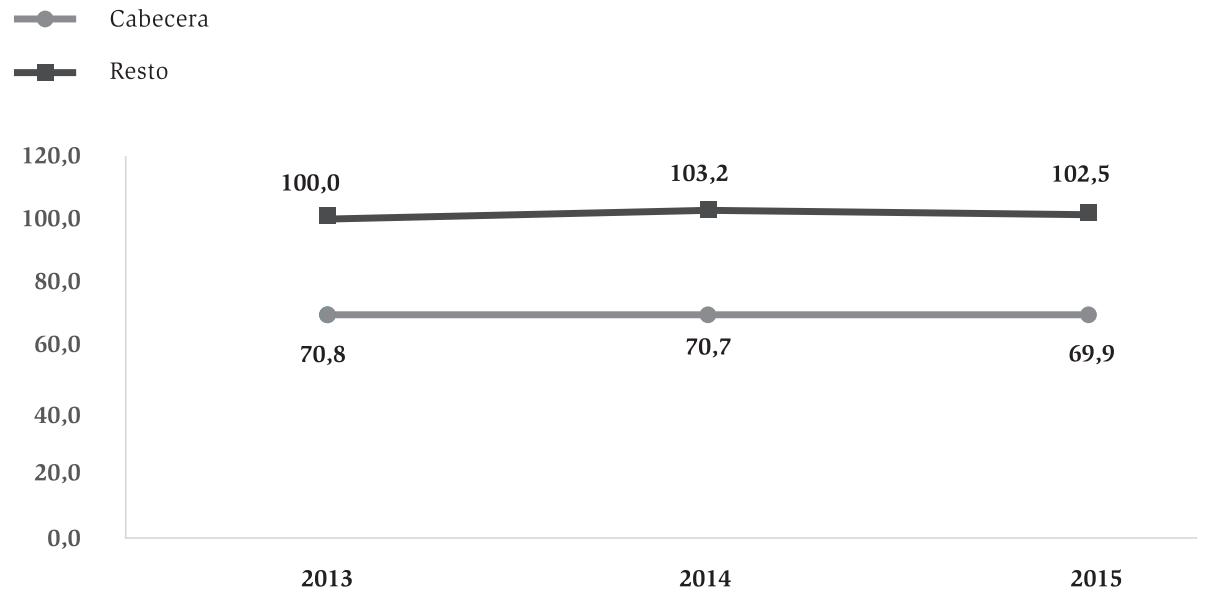

Fuente: Elaboración propia con base en DANE-GEIH, (2013-2015).

Para el 2015, al desagregar la información por sexo, se tiene que los hombres en la zona resto reportaron una antigüedad en el trabajo de 9,4 años (113,3 meses) mientras que la antigüedad de las mujeres estuvo 3 años por debajo con 6,5 años (77,7 meses) de antigüedad. En la cabecera la proporción de años en el trabajo fue de 6,5 años $(77,4$ meses) para los hombres y 5,1 años (60,7 meses) para las mujeres.

\section{Tabla 15. Antigüedad en el trabajo - en meses - desagregado por sexo 2013-2015}

$\begin{array}{llccccc}\text { Año } & & & & & & 2015 \\ \text { Según sexo } & 77,9 & 62,1 & 78,5 & 61,1 & 77,4 & 70,7 \\ \text { Cabecera } & 108 & 80,8 & 114,3 & 77,13 & 113,3 & 77,7\end{array}$

Fuente: Elaboración propia con base en DANE-GEIH, (2013-2015). 


\subsection{Dimensión 7: estabilidad y seguridad en el trabajo}

Cuando se habla de trabajo decente es fundamental pensar en la igualdad de oportunidades e igualdad de trato en el trabajo. Sin embargo, la falta de información de otras categorías como orientación sexual, creencia religiosa, etnia, migrantes, entre otras, dificulta la medición de indicadores laborales para estas poblaciones. Las estadísticas con las que se cuentan son referentes a la diferenciación sexual, que son centrales para el análisis, por lo que los indicadores de esta dimensión están orientados a evidenciar las diferencias para hombres y mujeres en el mercado laboral por zonas geográficas del país. Contar con la medición de estos indicadores ayuda a monitorear los avances o retrocesos en el tema de la promoción de la igualdad de oportunidades y trato en el trabajo por parte de las autoridades competentes.

3.7.1. Segregación ocupacional por sexo -Índice de disimilitud de Duncan-

La segregación ocupacional se presenta cuando existe la tendencia de asignar determinado tipo de ocupaciones a determinados grupos de una sociedad sin que esta separación esté relacionada directamente con la naturaleza y aptitudes propias del tipo de ocupación. Esta segregación es de dos tipos, por un lado, la segregación vertical en la que se mira la distribución de hombres y mujeres a través de distintas posiciones ocupacionales, por otro lado, la segregación horizontal en que se visualiza la distribución de hombres y mujeres dentro de una misma posición ocupacional para distintos sectores o ramas de actividad económica.

La OIT (2013) recomienda tres tipos de medición para la segregación, 1) La cuota femenina del empleo (en relación a la participación masculina) en cada uno de los subgrupos principales de la Clasificación Internacional Uniforme de Ocupaciones (CIUO); 2) La distribución ocupacional del empleo por sexo (usando subgrupos principales) y 3) el 
Índice de Disimilitud de Duncan. En este caso se utiliza la tercera forma de medición por ser el indicador más completo y popular para medir la segregación.

El índice consiste, básicamente, en la sumatoria de las diferencias de participación porcentual de mujeres y hombres en cada ocupación, 82 ocupaciones para el caso de Colombia sobre la base de la CIUO-88. Este índice puede ser entre 0 y 1 , donde 0 significa no segregación ocupacional y 1 segregación ocupacional completa entre los dos sexos. Un incremento en el índice de disimilitud significará una mayor tendencia de los hombres o las mujeres para desarrollar trabajos diferentes.

Los resultados que se presentarán a continuación están expresados en porcentaje. La zona resto en comparación con la cabecera presentó mayor segregación, alrededor de un pp para el 2015. En 2013 la zona resto presentó un índice de disimilitud de Duncan del 53,3\%, mientras en la cabecera fue de 52,0\%, para culminar en 2015 con un índice de 52,9\% y $51,7 \%$ respectivamente.

\section{Gráfico 20. Segregación ocupacional por sexo 2013-2015}

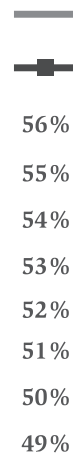

Cabecera

\section{Resto}

$56 \%$

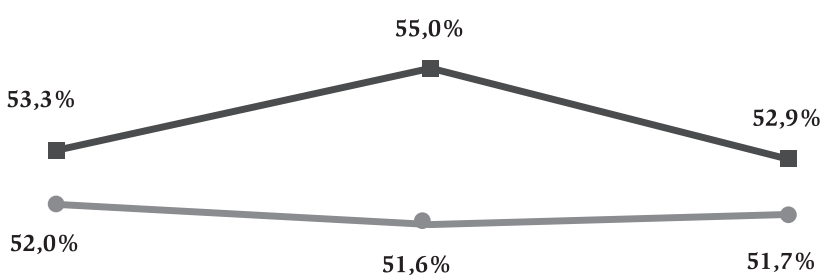

2013

2014

2015

Fuente: Elaboración propia con base en DANE-GEIH, (2013-2015). 
3.7.2. Porcentaje de mujeres ocupadas en alta y media gerencia

El indicador se refiere a la proporción de mujeres en cargos de media y alta gerencia en el sector público y privado. Tiene en cuenta los siguientes grupos ocupacionales: 1) los miembros del poder ejecutivo, de los cuerpos legislativos y personal directivo de la administración pública y 2) a los directores y gerentes generales de empresas privadas. Es un indicador que brinda información sobre la proporción de mujeres que están ocupadas en roles de toma de decisiones en el Gobierno, las empresas y las instituciones. Si bien en el sector público se han presentado algunos avances en la búsqueda de la igualdad de las condiciones entre hombres y mujeres en los cargos de decisión del Estado, aún falta mucho por hacer. En el sector privado la situación es aún más compleja, ya que las oportunidades para unos y para otras están determinadas por factores culturales y dinámicas económicas que brindan continuidades y cambios.

De acuerdo con los resultados encontrados, tanto en la zona resto como en la cabecera, la participación de las mujeres en los cargos de rango superior y medio fue muy baja, la situación más alarmante se presentó en la zona resto. Para el 2015, en la zona resto, solo el 3,4\% de las mujeres se desempeñaban en un cargo de dirección o autoridad, así las cosas los hombres eran los que estaban en la cabeza de las organizaciones. En el caso de la cabecera la participación de las mujeres en cargos de alta y media gerencia fue un poco mayor. Para el último año el $13,6 \%$ de las mujeres ocupadas hacían parte de este grupo, porcentaje invariable en el transcurso de los años. 


\section{Gráfico 21. Porcentaje de mujeres ocupadas en alta y media gerencia 2013-2015}

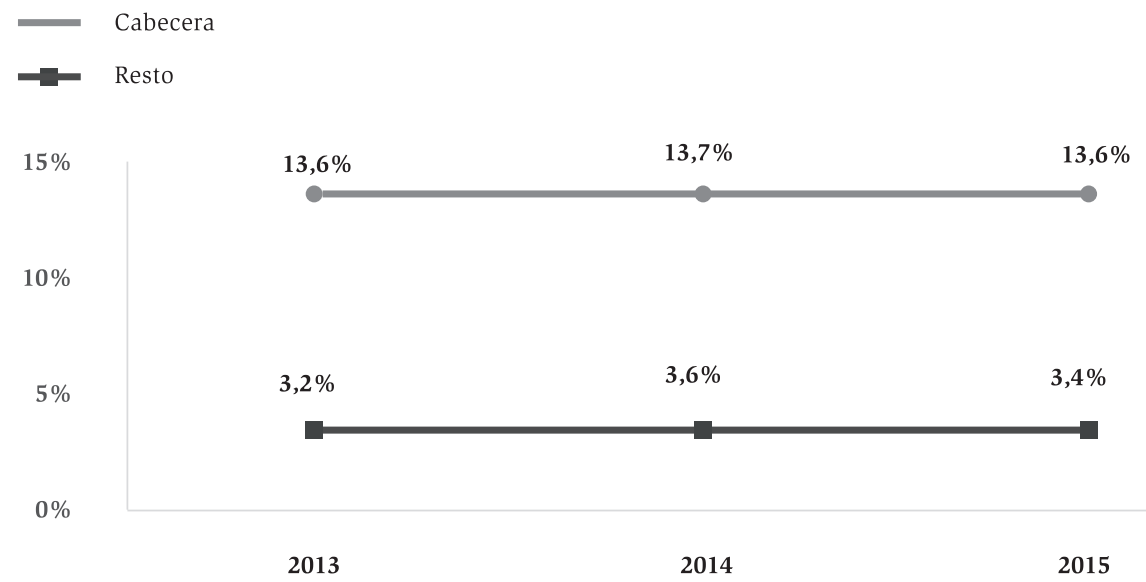

Fuente: Elaboración propia con base en DANE-GEIH, (2013-2015).

\subsubsection{Brecha salarial}

Este indicador refleja la discriminación y las desigualdades por género en el mercado laboral, infortunadamente las mujeres son las más afectadas. Si bien se han evidenciado incrementos en la participación de las mujeres, ellas perciben retribuciones promedio inferiores a las de los hombres, lo que deja ver una diferencia entre los salarios de unas y otros. La brecha salarial por género mide la diferencia relativa entre el salario promedio por hora de los hombres y el salario promedio por hora de las mujeres. El impacto que este indicador tiene sobre las mujeres es que obtienen menos ingresos a lo largo de su vida, lo que conduce a pensiones más bajas y a un mayor riesgo de estar en la pobreza en la tercera edad.

Tanto en la zona resto como en la cabecera la brecha salarial de género tuvo una tendencia variable en estos tres años de análisis, en la zona 
resto dicha tendencia fue mucho mayor. En el 2015 la brecha aumentó en 1,4 pp con respecto a 2014. En el caso de la cabecera, presentó una brecha menor que en la zona resto, y se ubicó en 6,6\%, disminuyendo en solo 0,5 pp de 2014 a 2015.

\section{Gráfico 22. Brecha salarial por sexo 2013-2015}

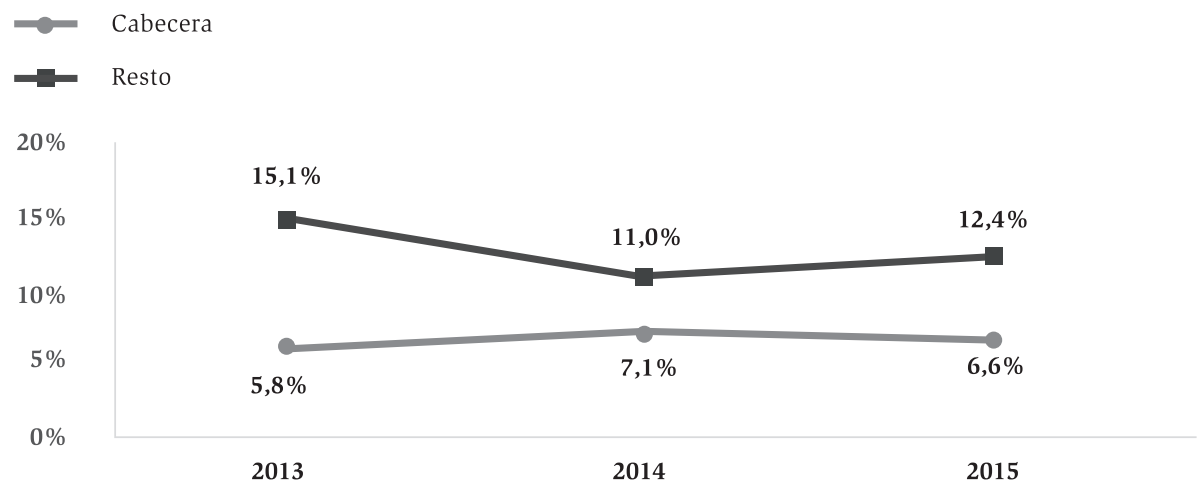

Fuente: Elaboración propia con base en DANE-GEIH, (2013-2015).

\subsection{Dimensión 8: entorno de trabajo seguro}

De acuerdo con la OIT (2016), cada quince segundos un trabajador muere a causa de accidentes o enfermedades relacionadas con el trabajo. Cada quince segundos 153 trabajadores tienen un accidente laboral. El coste de esta adversidad diaria es enorme y la carga económica de las malas prácticas de seguridad y salud se estima en un cuatro por ciento del Producto Interior Bruto global de cada año. Por lo anterior, la seguridad y salud en el trabajo son componentes vitales del trabajo decente. Las entidades nacionales, gubernamentales y municipales deben proteger a los y las trabajadoras de los riesgos y peligros relacionados con el trabajo, para esto no solo debe existir cobertura universal en afiliación a riesgos laborales, sino que debe haber un monitoreo, vigilancia y control de indicadores relacionados con la problemática. 


\subsubsection{Muertes laborales}

En el sector de la agricultura, la ganadería, la caza, la silvicultura y la pesca se ha presentado una disminución en el número de muertes a causa del trabajo en el periodo de análisis, pues se pasó de 47 muertes en 2013 a 33 en 2014 y culmina en 2015 con 38 muertes. Así mismo, se ha presentado una disminución en la tasa de mortalidad. Para 2015 por cada 10.000 afiliados al sistema de riesgos laborales se presentaron 1,1 muertes a causa del trabajo.

\section{Tabla 16. Muertes y tasa de mortalidad 2013-2015}

\begin{tabular}{|llll|}
$\begin{array}{l}\text { Agricultura, } \\
\text { ganadería, caza, } \\
\text { silvicultura y pesca }\end{array}$ & $\mathbf{2 0 1 3}$ & $\mathbf{2 0 1 4}$ & $\mathbf{2 0 1 5}$ \\
\hline Número de muertes & 47 & 33 & 38 \\
\hline Tasa de mortalidad* & 1,5 & 1,0 & 1,1 \\
\hline
\end{tabular}

Fuente: Fasecolda. RL Datos Riesgos Laborales

*Tasa de mortalidad por cada 10.000 afiliados al sistema de riesgos laborales.

\subsubsection{Accidentes de trabajo no mortales}

Los accidentes de trabajo son más recurrentes de lo esperado. En el sector de la agricultura, la ganadería, la caza, la silvicultura y la pesca; la accidentabilidad laboral se ha incrementado en los últimos años: pasó de 59.777 accidentes calificados en 2013 a 64.173 accidentes en 2015, lo que se traduce en 4.396 accidentes más en dos años. En 2015 la tasa de accidentabilidad del sector fue de $18,4 \%$, es decir, de cada 100 afiliados al sistema de riesgos laborales, 18,4 tuvo un accidente calificado como laboral. Para este último año se presentaron en promedio 176 accidentes por día.

También se encontró que para el 2015 a treinta y un trabajadores que presentaron un accidente de trabajo se les inició el pago de una pensión por invalidez y a 782 se les pagó una indemnización por incapacidad permanente parcial. 
Tabla 17. Número de accidentes de trabajo y tasa de accidentabilidad 2013-2015

\begin{tabular}{|llll|}
\hline Agricultura, ganadería, caza, silvicultura y pesca & $\mathbf{2 0 1 3}$ & $\mathbf{2 0 1 4}$ & $\mathbf{2 0 1 5}$ \\
\hline Número de accidentes de trabajo calificados & 59.777 & 61.209 & 64.173 \\
\hline Tasa de accidentabilidad* & 19,5 & 19,0 & 18,4 \\
\hline Número de pensiones de invalidez por accidente de trabajo** & 33 & 76 & 31 \\
\hline $\begin{array}{l}\text { Número de indemnizaciones IPP*** pagadas por accidentes de } \\
\text { trabajo }\end{array}$ & 610 & 770 & 787 \\
\hline
\end{tabular}

Fuente: Fasecolda. RL Datos riesgos laborales

*Tasa de accidentabilidad por cada 100 afiliados al sistema de riesgos laborales.

** Pérdida de capacidad laboral mayor o igual a 50\%.

*** Incapacidad permanente parcial (pérdida de capacidad laboral mayor o igual al 5\% y menor al $50 \%$ ).

\subsubsection{Inspección laboral}

Para la OIT (2016) una aplicación adecuada de la legislación del trabajo depende de una eficaz inspección del trabajo. Los inspectores del trabajo examinan cómo se aplican las normas nacionales del trabajo en el lugar de trabajo y aconsejan a los empleadores y a los trabajadores, respecto de la manera de mejorar la aplicación de la legislación nacional, en cuestiones tales como el tiempo de trabajo, los salarios, el trabajo infantil y la seguridad y la salud en el trabajo. Desempeñan una importante función en la garantía de que la legislación del trabajo se aplique de modo igualitario a todos los empleadores y trabajadores.

Infortunadamente en Colombia el sistema de inspección laboral está diseñado para atender las zonas urbanas y el sector formal de la economía, por ello atienden casi en su totalidad a trabajadores asalariados pero dejan por fuera a los trabajadores del sector rural que se encuentran en la informalidad. No existe un sistema de inspección para el sector rural ni recursos económicos o logísticos para realizar este tipo de inspecciones. Los inspectores no reciben formación especializada ni tienen un progra- 
ma que demarque el campo de acción en el sector rural. Lo anterior es una muestra de la deficiente aplicación de las obligaciones contenidas en el convenio 129 de OIT sobre inspección en el sector agrícola.

\subsection{Dimensión 9: seguridad social}

Para la OIT la seguridad social cubre todos los beneficios, en efectivo o en especie, que proveen protección social a los y las trabajadores ante los riesgos causados por: a) falta de ingresos laborales a causa de enfermedad, invalidez, maternidad, accidentes de trabajo, desempleo, vejez o muerte de un familiar; b) falta de acceso o acceso inasequible a la atención médica; c) falta de apoyo familiar, especialmente para niños y dependientes y d) pobreza general y exclusión social.

El acceso a un nivel adecuado de protección social es considerado un instrumento para la promoción del bienestar humano y el consenso social, que favorece la paz social y es indispensable para lograrla y, por lo tanto, para mejorar el crecimiento equitativo, la estabilidad social y el desempeño económico, lo que contribuye a la competitividad. Solo $20 \%$ de la población mundial tiene una protección social adecuada y más de la mitad no tiene ninguna cobertura. Estas personas enfrentan peligros en el lugar de trabajo y tienen pensiones y seguros de salud débiles o inexistentes.

\subsubsection{Participación de los beneficios de pensiones de vejez}

Este indicador corresponde a la población que actualmente está cubierta por el riesgo de disminución de la capacidad laboral en edad adulta mayor. Los resultados reflejan enormes diferencias entre las distintas zonas geográficas del país y no varían mucho de año a año. Para el 2015 solo el 7,5\% de los adultos de la zona rural recibieron una pensión, es decir, que más del $90 \%$ del total de adultos mayores estaban excluidos de esta protección. En la cabecera la participación fue de 30,3\%. 


\section{Gráfico 23. Porcentaje de población adulta que recibe} pensión de vejez 2013-2015

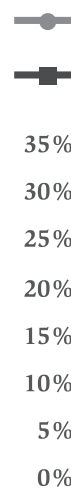

Cabecera

Resto

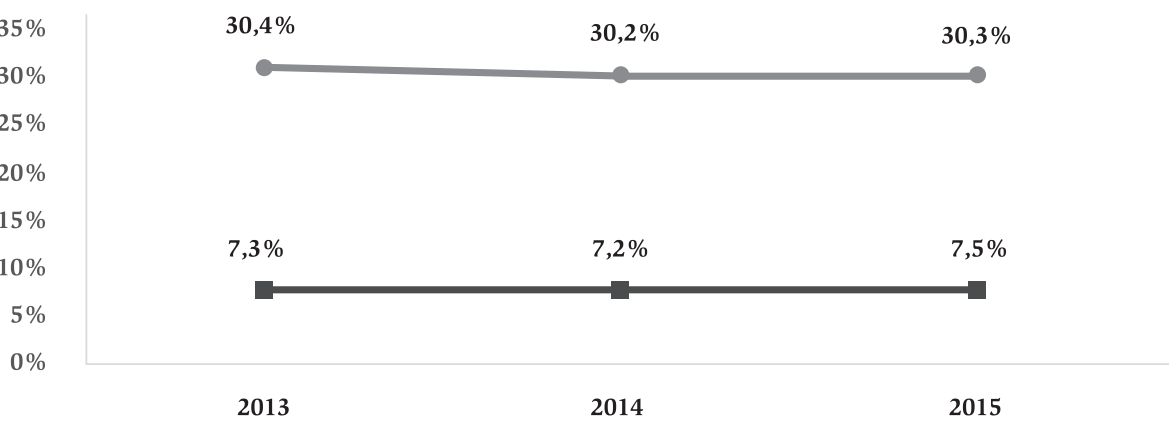

Fuente: Elaboración propia con base en DANE-GEIH, (2013-2015).

Al mirar la información desagregada por sexo se encontró que el porcentaje de mujeres adultas que percibía una pensión fue inferior al porcentaje de hombres adultos. En 2015 solo el 5,0\% de las mujeres adultas de la zona resto recibieron una pensión, frente a un 10,6\% de los hombres adultos que percibieron una pensión de vejez. En la cabecera la situación fue de $25,2 \%$ frente a $39,8 \%$ respectivamente.

Tabla 18. Participación de los beneficiarios de pensiones de vejez desagregada por sexo 2013-2015

\begin{tabular}{|c|c|c|c|c|c|c|}
\hline Año & \multicolumn{2}{|c|}{2013} & \multicolumn{2}{|c|}{2014} & \multicolumn{2}{|c|}{2015} \\
\hline Según sexo & ตึ. & ఝึ & पె. & ఝึ & ตึ. & ๓ึ \\
\hline Cabecera & $40,0 \%$ & $25,2 \%$ & $38,9 \%$ & $25,6 \%$ & $39,8 \%$ & $25,2 \%$ \\
\hline Resto & $10,4 \%$ & $4,8 \%$ & $9,6 \%$ & $5,3 \%$ & $10,6 \%$ & $5,0 \%$ \\
\hline
\end{tabular}

Fuente: Elaboración propia con base en DANE-GEIH, (2013-2015). 
Este panorama es el reflejo de la marcada informalidad en el sector rural que afecta a la población más vulnerada, muy pobre, que a su vez presenta las menores tasas de afiliación a pensión pero las mayores tasas de afiliación a salud a través del régimen subsidiado (Santa María, Parad y Mujica, 2009).

3.9.2. Proporción de la Población Económicamente Activa (PEA) que cotiza en un fondo de pensión -obligatorio-

El indicador hace referencia a la fuerza laboral que potencialmente estará cubierta en el futuro con seguridad social en pensiones. Los resultados indican que un alto porcentaje de la población de la zona resto estaba excluido del sistema. Para el 2015 solo el 11,8\% de la PEA de esta zona cotizaba a un fondo de pensiones mientras que en la cabecera la cotización llegó a 37,5\% .

\section{Gráfico 24. Proporción de la PEA que cotiza en un fondo} de pensiones -obligatorio- 2013-2015

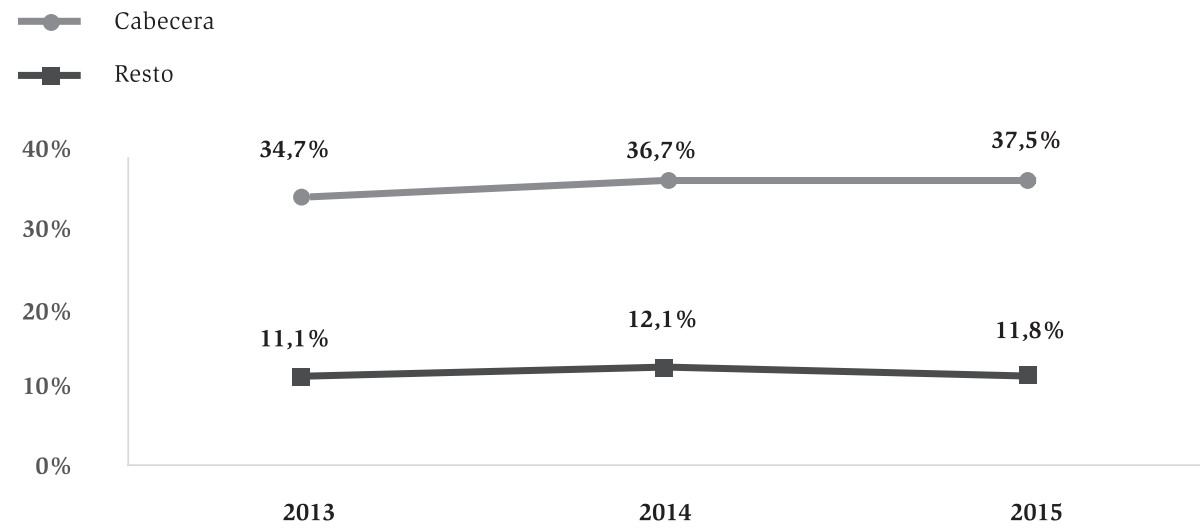

Fuente: Elaboración propia con base en DANE-GEIH, (2013-2015). 
El gran interrogante de los resultados encontrados tiene que ver con los trabajadores y trabajadoras excluidas del sistema pensional en ambas zonas del país, pues se ha evidenciado que el sistema pensional en el país está diseñado exclusivamente para garantizarles derechos a los trabajadores de la economía formal, con un contrato de trabajo y que gocen de una relativa estabilidad a lo largo de su vida laboral.

Desagregando este indicador por sexo, se encontró que en la zona resto más del $90 \%$ de las mujeres no cotizaba a un fondo de pensión; de cada 100 mujeres solo cotizaron 9,6, y de cada 100 hombres solo cotizaron 12,8. En la cabecera la situación fue menos grave, la relación fue de 34,9 y 39,7 respectivamente.

Tabla 19. Proporción de la Población Económicamente Activa (PEA) que cotiza en un fondo de pensión -obligatorio- desagregada por sexo 2013-2015

\begin{tabular}{|c|c|c|c|c|c|c|}
\hline Año & \multicolumn{2}{|c|}{2013} & \multicolumn{2}{|c|}{2014} & \multicolumn{2}{|c|}{2015} \\
\hline Según sexo & पึ. & यి & पె. & 我 & חึ. & m \\
\hline Cabecera & $36,7 \%$ & $32,3 \%$ & $38,8 \%$ & $34,3 \%$ & $39,7 \%$ & $34,9 \%$ \\
\hline Resto & $12,4 \%$ & $8,2 \%$ & $13,3 \%$ & $9,5 \%$ & $12,8 \%$ & $9,6 \%$ \\
\hline
\end{tabular}

Fuente: Elaboración propia con base en DANE-GEIH, (2013-2015).

3.10 Dimensión 10: diálogo social, representación de los trabajadores y empleadores

El diálogo social desempeña un papel decisivo en alcanzar el objetivo de promoción de oportunidades para que mujeres y hombres obtengan trabajo decente y productivo en condiciones de libertad, igualdad, seguridad y dignidad humana. La definición de diálogo social de la OIT incluye todos los tipos de negociación, consulta e intercambio de 
información entre representantes de gobiernos, empleadores y trabajadores sobre temas de interés común (Organización Internacional del Trabajo, 2016).

Las estructuras y los procesos del diálogo social, cuando son exitosos, tienen el potencial de resolver importantes temas económicos y sociales, promover una buena gobernanza, avanzar en la paz y estabilidad social e industrial, y estimular el progreso económico. La eficacia del diálogo social depende de

- Respeto de los derechos fundamentales de libertad sindical y negociación colectiva. Medición y análisis de las condiciones de trabajo decente en las zonas geográficas de Colombia 101

- Organizaciones de trabajadores y empleadores fuertes e independientes con la capacidad técnica y los conocimientos necesarios para participar en el diálogo social.

- Voluntad política y compromiso de todos los participantes al intervenir en el diálogo social.

- Respaldo institucional adecuado.

Los indicadores de diálogo social son elementos fundamentales cuando se mide el progreso del trabajo decente. Para esta dimensión se utilizan dos indicadores principales, la tasa de sindicalización y la dinámica de la negociación colectiva.

\subsubsection{Tasa de sindicalización}

En Colombia el sindicalismo es prácticamente marginal en las relaciones laborales, para el 2015 se estimó una tasa de sindicalización de 4,6\%. De acuerdo con el Subsistema Censo Sindical de la Escuela Nacional Sindical (ENS), la tasa de sindicalización del sector de la agricultura, la ganadería, la caza, la silvicultura y la pesca se ubicó en 2,6\%, 2 pp 
menos de la reportada a nivel nacional, es decir, de cada 100 ocupados en este sector económico solo 2,6 estaban afiliados a un sindicato.

\subsubsection{Dinámica de la negociación colectiva}

Según el subsistema de la Dinámica de la Contratación Colectiva de la ENS, en 2014 se presentaron 71 casos de negociación colectiva en el sector de la agricultura, la ganadería, la caza, la silvicultura y la pesca, de los cuales 28 fueron convenciones colectivas de trabajo y 43 pactos colectivos. Para el 2015 el número de negociaciones cambió significativamente, se presentaron 128 casos, allí se destacó el incremento de las convenciones colectivas que llegaron a 102, mientras que los pactos colectivos llegaron a 26.

\section{Tabla 20. Dinámica de la Negociación Colectiva en la Agricultura, ganadería, caza, silvicultura y pesca 2014-2015}

\begin{tabular}{lll} 
Tipo de Negociación & Año & $\begin{array}{l}\text { Agricultura, ganadería, caza, } \\
\text { silvicultura y pesca }\end{array}$ \\
\hline Convenciones Colectivas & 2014 & 28 \\
& Trab. Beneficiarios & 2.356 \\
& 2015 & 102 \\
& Trab. Beneficiarios & 22.821 \\
\hline Pactos Colectivos & 2014 & 43 \\
& Trab. Beneficiarios & 10.273 \\
& 2015 & 26 \\
& Trab. Beneficiarios & 6.315
\end{tabular}

Fuente: Escuela Nacional Sindical, Sistema de información Sindical y Laboral (Sislab), Subsistema Dinámica de la Contratación Colectiva, con datos del Ministerio de Trabajo. El dato de trabajadores beneficiarios fue suministrado por el Ministerio para el $72 \%$ de los casos en el 2004 y para el $88 \%$ de los casos en el 2015. Se debe tener en cuenta que en el año 2015 se realizó la hegociación de Sintrainagro con los empresarios bananeros que es una negociación que beneficia a más de 18.000 trabajadores y genera alrededor de 80 convenciones 


\section{Conclusiones y recomendaciones}

Como se ha podido constatar, la medición del trabajo decente no es un proceso mediado por un indicador sintético que revele un único dato, al contrario, es un proceso multidimensional, por ello es un concepto complejo. Las distintas dimensiones del trabajo decente se encuentran interrelacionadas, por lo cual las estrategias e instrumentos que se definan deben atender de manera transversal las carencias encontradas.

El concepto de trabajo decente tiene un carácter normativo en términos de que es un deber ser al cual se llega de manera progresiva avanzando en cada una de las dimensiones señaladas. El diagnóstico presentado muestra los obstáculos y el déficit de trabajo decente que se tiene en esta zona del país.

En la dimensión 1 -oportunidades de empleo- quedan retos planteados frente a las diferencias encontradas en los diferentes indicadores por sexo, pues las mujeres son las más afectadas. También debe convertirse en un desafío la reducción de la precariedad laboral y de los riesgos en el empleo, interpretados a la luz de la situación de los trabajadores por cuenta propia, que representan más del $50 \%$ de los ocupados y de los trabajadores familiares; así como no puede dejarse de lado el seguimiento a los ninis y la reducción de la informalidad laboral.

Con respecto a la dimensión 2 -ingresos suficientes y productividad-, el Estado debe definir metas claras en sus programas que reduzcan situaciones de pobreza, como lo indica la tasa de trabajadores pobres que corresponde a más del $40 \%$ de la población. Además, estas metas deben impactar en el cierre de la brecha de ingresos entre los trabajadores de la zona cabecera y de la zona resto.

La dimensión 3 -tiempo de trabajo decente- evidenció que un porcentaje importante de trabajadores labora más horas de las permitidas. Esta situación no es favorable para el trabajo decente bajo el entendido 
de que dichas jornadas tienen incidencia sobre la salud, la recreación, la familia y el descanso del trabajador.

Sobre la dimensión 4 -conciliación del trabajo, la vida familiar y la vida personal - se identificó que los trabajadores dedican más del $90 \%$ de su tiempo a actividades no remuneradas, lo cual no sería grave si dichas actividades estuvieran asociadas con el fortalecimiento de la fuerza de trabajo y mejoras en el capital humano; pero, al revisar la desagregación por sexo, llama la atención la significativa distancia que hay entre hombre y mujeres, pues ellas son las que dedican más del ciento por ciento del tiempo a actividades no remuneradas y del cuidado.

En la dimensión 5 - trabajo que debería abolirse- las cifras encontradas son de especial atención, más cuando existe una Estrategia Nacional para la Erradicación del Trabajo Infantil y Protección del Joven Trabajador que plantea las estrategias y los estamentos encargados de la superación de esta problemática. Para erradicar el trabajo infantil son necesarias acciones contundentes que garanticen condiciones de trabajo decente para los ocupados de la zona, así mismo acciones encaminadas a fortalecer las instituciones públicas encargadas de la política y fortalecer el sistema de inspección, vigilancia y control.

La dimensión 6 - estabilidad y seguridad del trabajo - indica que más del $90 \%$ de la población ocupada se encontraba en un empleo precario y no tuvo avances significativos en el tiempo. Para avanzar hacia el trabajo decente es necesario realizar campañas dirigidas a la promoción y cumplimiento de los derechos laborales, promoción de la legalidad y formalización laboral, además concertar con las organizaciones sindicales un plan de inspección laboral en la zona.

Con respecto a la dimensión 7 —igualdad de oportunidades y trato en el trabajo - se evidencia una distorsión del mercado laboral, tanto en la zona cabecera como en el resto, y corresponde a las diferencias marca- 
das en los indicadores principales del trabajo para mujeres y hombres, de nuevo son ellas las menos favorecidas. Se encontró que las mujeres participaron poco en los roles de toma de decisiones de las instituciones públicas y privadas. Por lo tanto, realizar una medición de trabajo decente diferenciado por sexo es importante para el direccionamiento de políticas públicas efectivas que disminuyan las brechas existentes entre unas y otros.

Para la dimensión 8 -entorno de trabajo seguro- se encontró un aumento de la muerte a causa del trabajo y un destacado incremento en el número de accidentes de trabajo calificado. Contar con información actualizada sobre las condiciones de seguridad ocupacional y laboral de los y las trabajadoras de la zona resto permitirá que los actores del mundo del trabajo tengan instrumentos de medición para establecer políticas de prevención y protección relacionadas con la seguridad y salud laboral. Además, es necesario el fortalecimiento de los mecanismos de inspección, vigilancia y control que mitiguen la problemática.

La medición para la dimensión 9 -seguridad social- evidencia un cambio marginal en la población masculina mayor de 62 años y la femenina mayor de 57 años que recibe una pensión de vejez y un decrecimiento de la PEA que cotiza a un fondo de pensión. Ante este panorama es necesario el fortalecimiento del sistema de inspección, vigilancia y control que impida la violación de los derechos laborales de la población trabajadora.

Por último, para la dimensión 10 —diálogo social, representación de los trabajadores y empleadores - los resultados indican la poca afiliación de los ocupados en organizaciones sindicales y la marginal participación de la negociación colectiva en el sistema de relaciones laborales. Para progresar en trabajo decente es necesario el respeto de la libertad sindical (asociación, negociación y huelga) como derecho fundamental en el trabajo. 
Los resultados encontrados reafirman la necesidad de intervenir en la zona resto con políticas públicas laborales eficientes que logren: a) estabilidad en el empleo mediante formas adecuadas de contratación, transición hacia la formalidad; b) promoción del empleo juvenil en la economía rural; c) erradicar el trabajo infantil y sus peores formas; d) remuneraciones suficientes; e) cobertura y acceso a protecciones sociales; f) fortalecimiento del sistema especial de seguimiento laboral en el sector rural, cumplimiento de las obligaciones contenidas en el Convenio 129 de la OIT sobre inspección laboral en el sector agrícola y g) asegurar la libertad sindical y el reconocimiento efectivo del derecho de negociación colectiva.

\section{Referencias bibliográficas}

Departamento Administrativo Nacional de Estadística (2015). Microdatos Gran encuesta integrada de hogares 2013-2014 y 2015. Recuperado de http:// formularios.dane.gov.co/Anda_4_1/index.php/catalog/MICRODATOS.

Departamento Administrativo Nacional de Estadística (2016). Ficha metodológica Gran encuesta integrada de hogares. Recuperado de http://www. dane.gov.co/files/investigaciones/fichas/empleo/ficha_metodologica_ GEIH-01_V10.pdf.

Departamento Administrativo Nacional de Estadística (2015). Encuesta nacional de calidad de vida. Anexos. Recuperado de http://www.dane.gov.co/ index.php/estadisticas-por-tema/salud/calidad-de-vida-ecv/encuesta-nacional-de-calidad-de-vida-ecv-2015

Departamento Administrativo Nacional de Estadística (2015). Gran encuesta integrada de hogares. Módulo de trabajo infantil. Recuperado de http:// www.dane.gov.co/index.php/estadisticas-por-tema/mercado-laboral/trabajo-infantil.

Departamento Administrativo Nacional de Estadística (2014). Censo Nacional Agropecuario. Recuperado de http://www.dane.gov.co/index.php/estadisticas-por-tema/agropecuario/censo-nacional-agropecuario-2014. 
Departamento Administrativo Nacional de Estadística (2013). Encuesta nacional de uso del tiempo. Recuperado de http://www.dane.gov.co/index.php/ estadisticas-por-tema/pobreza-y-condiciones-de-vida/encuestanacionaldel-uso-del-tiempo-enut

De Hoyos, R., Rogers H. y Székely M. (2016). Ninis en América Latina, 20 millones de jóvenes en busca de oportunidades. Washington D. C.: Grupo Banco Mundial. Recuperado de https://openknowledge.worldbank.org/ bitstream/handle/10986/22349/K8423.pdf?sequence $=5$

Departamento Nacional de Planeación (2015). Misión para la Transformación del Campo. La protección social de la población rural. Bogotá: Cepal. Recuperado de https://colaboracion.dnp.gov.co/CDT/Agricul turapecuarioforestal \% 20y \% 20pesca/La \% 20protecci \% C3 \% B3n \% 20social \% 20 de\%20la \%20poblacion \% 20rural.pdf

Departamento Nacional de Planeación (2014). Misión para la Transformación del Campo. Diagnóstico de las condiciones sociales del campo colombiano. Bogotá: Dirección de Desarrollo Rural Sostenible y Dirección de Desarrollo Social. Recuperado de https://colaboracion.dnp.gov. co/CDT/Agriculturapecuarioforestal \% 20y \% 20pesca/2014_10_30\%20 DIAGN\% \%3 \% 93STICO \% 20SOCIAL.PDF

Escuela Nacional Sindical (2015). Sistema de Información Sindical y Laboral -Sislab-, Subsistema Dinámica de la Contratación Colectiva. Base de datos propia.

Escuela Nacional Sindical (2015). Sistema de Información Sindical y Laboral -Sislab-, Subsistema Censo Sindical. Base de datos propia.

Federación de Aseguradores Colombianos (2016). RLDatos Riesgos Laborales. Recuperado de https://sistemas.fasecolda.com/rldatos/.

Ferreira, F., Messina Julián, R., Jamele et al. (2013). Economic Mobility and the Rise of the Latin American Middle Class. Washington, D.C.: Banco Mundial.

Grogger, J. (1997). Market Wages and Youth Crime. Cambridge: National Bureau of Economic Research.

Jacob, B. y Lefgren, L. (2003). Are Idle Hands the Devil's Workshop? Incapacitation, Concentration, and Juvenile Crime. The American EconomicReview, 93(5), 1560-77. 
Martínez, L. (1992). El empleo rural en el Ecuador. Quito: Inem, Ildis. Recuperado de http://www.flacsoandes.edu.ec/libros/digital/56176.pdf

Merchán, C. (2014). Sector rural colombiano: Dinámica laboral y opciones de afiliación a la seguridad social. Archivos de Economía, documento 410. Departamento Nacional de Planeación.

Organización Internacional del Trabajo (2016). Trabajo decente. Recuperado de http://www.ilo.org/global/topics/decent-work/lang--es/index.htm.

Organización Internacional del Trabajo (2016). Inspección del trabajo. Recuperado de http://www.ilo.org/global/standards/subjectscovered-byinternational-labour-standards/labour-inspection/lang--es/index.htm.

Organización Internacional del Trabajo (2016). Diálogo social. Recuperado de: http://www.ilo.org/public/spanish/dialogue/themes/sd.htm.

Organización Internacional del Trabajo (2016). Seguridad y salud en el trabajo. Recuperado de: http://www.ilo.org/global/topics/safety-andhealthat-work/lang--es/index.htm.

Organización Internacional del Trabajo (2013). Decent Work Indicators. Guidelines for producers and users of statistical and legal framework indicators. Recuperado de http://www.ilo.org/wcmsp5/groups/public/---dgreports/--stat/documents/publication/wcms_223121.pdf.

Organización Internacional del Trabajo (2002). Un futuro sin trabajo infantil. Informe global con arreglo al seguimiento de la declaración de la OIT relativa a los principios y derechos fundamentales en el trabajo. Informe del director general. Conferencia Internacional del Trabajo, 90.a reunión, 2002. Recuperado de http://www.ilo.org/global/publications/ilobookstore/order-online/books/WCMS_PUBL_9223124166_SP/lang--es/index.htm

Osorio, V. y Tangarife, C. (2015). De Cuidados y Descuidos. La economía del cuidado en Colombia y perspectivas de política pública. Medellín: Escuela Nacional Sindical.

Pineda, J. (2013). El trabajo decente en Bogotá: Diagnóstico, análisis y perspectivas. Bogotá: Universidad de Los Andes. 
República de Colombia (2016). Acuerdo final para la terminación del conflicto y la construcción de una paz estable y duradera. Alto Comisionado para la Paz. Recuperado de http://www.altocomisionadoparalapaz.gov.co/ procesos-y-conversaciones/Documentos \%20compartidos/24-11-2016NuevoAcuerdoFinal.pdf

Renos, V., Rigolini, J, y Lucchetti, L. (2015). Left Behind: Chronic Poverty in Latin America and the Caribbean. Washington, D. C: Banco Mundial.

Santa María, M., Parad, C. F., y Mujica, A. V. (2009). Tendencias recientes en la creación de empleo en el sector rural en Colombia. Washington, D. C.: Banco Mundial. Recuperado de http://documents.worldbank.org/curated/ pt/336141468027565516/pdf/519300WP0P11051Box345544B01PUBLIC1.pdf 